\title{
Differences and similarities between cancer and somatic stem cells: therapeutic implications
}

\author{
Fiorella Rossi ${ }^{1}$, Hunter Noren ${ }^{1}$, Richard Jove ${ }^{1}$, Vladimir Beljanski ${ }^{1 *}$ (D) and Karl-Henrik Grinnemo ${ }^{1,2,3^{*}}$
}

\begin{abstract}
Over the last decades, the cancer survival rate has increased due to personalized therapies, the discovery of targeted therapeutics and novel biological agents, and the application of palliative treatments. Despite these advances, tumor resistance to chemotherapy and radiation and rapid progression to metastatic disease are still seen in many patients. Evidence has shown that cancer stem cells (CSCs), a sub-population of cells that share many common characteristics with somatic stem cells (SSCs), contribute to this therapeutic failure. The most critical properties of CSCs are their self-renewal ability and their capacity for differentiation into heterogeneous populations of cancer cells. Although CSCs only constitute a low percentage of the total tumor mass, these cells can regrow the tumor mass on their own. Initially identified in leukemia, CSCs have subsequently been found in cancers of the breast, the colon, the pancreas, and the brain. Common genetic and phenotypic features found in both SSCs and CSCs, including upregulated signaling pathways such as Notch, Wnt, Hedgehog, and TGF- $\beta$. These pathways play fundamental roles in the development as well as in the control of cell survival and cell fate and are relevant to therapeutic targeting of CSCs. The differences in the expression of membrane proteins and exosome-delivered microRNAs between SSCs and CSCs are also important to specifically target the stem cells of the cancer. Further research efforts should be directed toward elucidation of the fundamental differences between SSCS and CSCs to improve existing therapies and generate new clinically relevant cancer treatments.
\end{abstract}

Keywords: Cancer stem cells, Somatic stem cells, Immunoregulation, Targeted therapy, Signaling pathways, Clinical trials, Cell surface markers, Cellular differentiation, Self-renewal

One of the major problems in the failure of cancer treatments is the presence of cancer stem cells (CSCs) - they are considered to be responsible for drug therapy resistance and thought to be involved in cancer initiation and metastasis. However, a successful therapy should have minimal side effects on normal somatic stem cells (SSCs). Understanding the differences in origin, mechanism of self-renewal, and signaling pathways of CSCs and SSCs

\footnotetext{
*Correspondence: vbeljanski@nova.edu; karl-henrik.grinnemo@surgsci.uu.se; karl-henrik.grinnemo@ki.se

${ }^{1}$ NSU Cell Therapy Institute, Nova Southeastern University, 3301 College Ave, 3200 South University Drive, Fort Lauderdale, FL 33328, USA

Full list of author information is available at the end of the article
}

will provide a better approach to target these specific populations in order to protect healthy cells and minimize side effects.

\section{The origin of cancer cells}

Cancer is one of the most pervasive causes of morbidity and mortality in the Western world; it is the second leading cause of death after cardiovascular disease, and one of the most pressing current problems in public health [1]. Cancer is described as a proliferative, invasive, and metastatic disease that is caused by an accumulation of genetic abnormalities that randomly produce a malignant cell [2]. Such abnormalities can be induced by chemical 
carcinogens, chronic inflammation, exposure to radiation, or by genetic predisposition [3]. Cancer originates when normal cells accumulate DNA mutations over time and lose the ability to grow and proliferate in a regulated manner, leading to unrestricted cell proliferation. Phenotypically and functionally, cancer cells are abnormal and unstable and show inter- and intra-tumor heterogeneity. Inter-tumor heterogeneity is manifested as the difference in tumor composition between different individuals for the same cancer type; while intra-tumor heterogeneity is described as differences between tumor cells inside of the same tumor [4]. Cancer cells can arise in almost any tissue but they are most commonly found in the breast, ovary, prostate, liver, stomach, pancreas, lung, brain, and bone marrow. Because of differences in genetic composition and oncogenic signaling, tumors in different tissues exhibit different behaviors. Pancreatic tumors, for example, have a tendency to be highly aggressive, while prostate tumors are more confined and easier to treat [5].

Cancer develops by the accumulation of mutations in genes leading to the deregulation of signaling pathways that initiate the acquisition of self-sufficient growth signals leading to insensitivity to anti-growth signals, evasion of apoptosis, unlimited replicative potential, sustained angiogenesis, and capacity to invade surrounding tissues [6]. The metastatic colonization is mainly accomplished by a sub-population of cancer cells that enter the blood stream allowing them to reach distant sites [7]. Clinically, cancer is classified according to a cancerspecific staging system, which together with the cancer type and grade are important parameters for successful treatment. The staging system is based on the size of the tumor, the extent of the lymph node spread, and the presence or absence of metastases [8]. Several genes have been shown to play a role in the initiation and progression of cancer. On a cellular level, cancer progression can be divided in different stages: tumor initiation, tumor progression, angiogenesis, and metastasis [9]. When these heterogeneous tumors are put under selection pressure by chemotherapy, a specific sub-population of resistant cells can selectively take over, allowing this sub-class to dominate the tumor [10]. Recently, it was identified that a small part of that heterogeneous population is composed of stem-like progenitor cells or CSCs that could originate from normal or stem cell mutations initiated by changes in the environment, by chronic inflammation, or by epithelial-to-mesenchymal transformation (EMT, discussed later) (Fig. 1) [11, 12]. Mutations in stem cell can occur by gradual accumulation of aging-induced genetic changes during lifetime [13]. Aging leads to a decrease of genome integrity resulting in increased cancer risk [14]. It was shown by Weinberg group that at least three to four cell type-specific mutations are require for cellular transformation in vitro $[15,16]$; these mutations also increases exponentially with age and aging is associated with increased clonal dominance of mutant stem and progenitor cells [14].

The strongest evidence for the CSC theory comes from studies in acute myelogenous leukemia (AML), when Bonnet and Dick performed serial transplantation

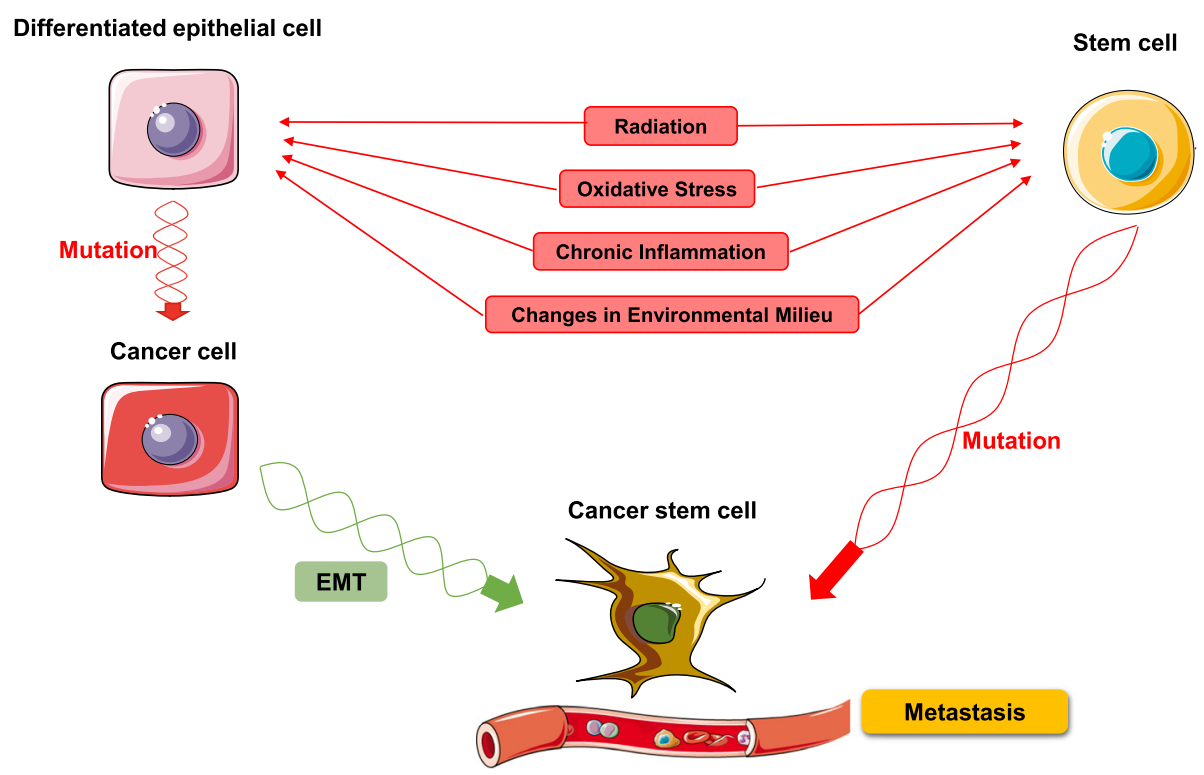

Fig. 1 Role of environmental milieu and chronic inflammation in CSC maintenance. When epithelial cells are exposed to stressors such as radiation, oxidative stress, chronic inflammation, or changes in its environmental milieu, mutations in DNA can occur. While stem cells can mutate directly into CSCs, epithelial cells require a two-step process: first, the initial stress causes it to mutate into a cancer cell; then, it can undergo epithelial-mesenchymal transition (EMT) to become a cancer stem cell capable of metastasis 
experiments to show that only rare cells with high selfrenewal capacity isolated from AML patients could initiate leukemia in murine models. Later the cell responsible for tumor initiation was identified by its phenotype as $\mathrm{CD}_{34}{ }^{+} \mathrm{CD} 38^{-}$, a remarkably common phenotype of a normal hematopoietic stem cell (HSC) [17]. Additional studies have supported the idea of CSCs and currently this idea is becoming commonly accepted $[18,19]$. While CSCs might represent a small fraction of the cells in the heterogeneous tumors, they likely play a fundamental role in cancer initiation, progression, and metastasis as well as in therapy failure [20]. CSCs are also called tumor-initiating cells since they possess several important properties of SSCs: self-renewal, unlimited proliferation potential, slow replication, resistance to drugs, and the capacity to differentiate, giving rise to daughter cells, which make up the bulk of the tumor. While CSCs can initiate tumor formation, their daughter cells are incapable of forming new tumors by metastasis [21]. There is some controversy regarding the origin of CSCs: while in most instances they may originate from normal stem cells, there are some CSCs that can arise from somatic cells. Since their origin is not clearly understood, the term tumor-initiating cells have been used to define these cells. In general, CSCs are considered the seed of the tumor mass which also promotes its growth [22].

Intriguingly, Scadden showed that somatic cells, which give rise to cancer cells, do not need to have stem cell properties but that a stem-like phenotype could be acquired during the process of tumorigenesis, which is further an indication of the tumor cells ability to adapt to environmental factors [23]. In this review, we will focus on the most important similarities and differences between SSCs and CSCs to examine potential avenues to target CSCs with minimal impact on SSCs.

\section{The biological function of somatic stem cells}

SSCs can undergo extensive cell division while retaining the ability to give rise to stem cells and cells that can differentiate into specialized cells [24]. Among the several characteristics of a SSC, the most important are self-renewal and multipotent differentiation capacity. Self-renewal is defined as a special cell division that enables stem cells to produce another stem cell with the same replication potential [25]. Self-renewal is achieved in response to systemic or local signals that induce cell proliferation while maintaining tissue-specific properties $[25,26]$. Another important function of SSCs involves cell differentiation of daughter cells into tissue-specific specialized cells, i.e., mature cells of a specific tissue [27]. SSCs repair damaged tissues and maintain normal tissue homeostasis by replenishing many cells throughout an organism's life [28, 29]. In addition, SSCs can be constantly under division, such as those found in the gut and bone marrow or can remain quiescent (non-dividing) for prolonged periods of time until activated [30]. Once activated by signals originating in their microenvironment, SSCs can contribute to tissue repair by differentiating into specialized cells by the action of paracrine and autocrine signals [31].

Stem cells can be classified according to their exclusive differentiation potential: totipotent (they can generate all cell types in the body including extra-embryonic tissue or placenta), pluripotent (they can generate all body cells including germ cells), multipotent (they can be further specialized in the tissue), and unipotent (they only generate a single cell type) [32]. Depending on the stage of embryonic development that the embryonic stem cells (ESCs) are derived, these can be totipotent or pluripotent [33], while adult or SSCs are shown to be multipotent [34].

ESCs and SSCs can be distinguished according to specific intracellular and surface markers. There are some transcription factors that are commonly expressed in ESCs, the so-called core nuclear factors, like Oct-3/4, Sox2, KLF4, and Nanog [35]. A wide range of cell surface markers characterizing ESCs have been reported, among the most common are the cluster of differentiation (CD) antigens surface proteins. $\mathrm{CD}$ antigens associated with pluripotency are CD9, CD24, and CD133. Additionally, ESCs express CD90, CD117 [36]. ESCs also express specific integrins that play a role in cell adhesion, signaling and cell migration. The most important are CD324 (E-cadherin) and CD29 ( $\beta 1$ integrin). Other proteins like TRA-1-60 and TRA-1-81, Frizzled5, and Cripto-1 are also characteristic of ESCs [36].

SSCs are thought to be tissue-specific, which means that they give rise to progeny that correspond to their tissue of origin. SSCs can be found in adult tissues like the intestine, skin, muscle, blood, and nervous system [37]. The two clinically utilized SSCs are HSCs and mesenchymal stromal cells (MSCs). HSCs are derived from the mesoderm and can be found in bone marrow and umbilical cord blood, and they give rise to blood cells during hematopoiesis and can be used in hematopoietic cell transplantation $[38,39]$. On the other hand, MSCs are progenitor cells that give rise to cells representing different mesenchymal lineages and can be found in virtually any tissue but especially adipose, bone marrow, umbilical cord, and possibly in the human testis [40]. The minimal criteria for MSCs are that they should be plastic-adherent in standard culture conditions, expression of CD73 (SH3), CD90, and CD150 (SH2) and lack of expression of CD11b, CD14, CD19, CD34, CD45, and HLA-DR molecules and be able to differentiate into chondrocytes, osteoblasts and adipocytes in vitro [41]. MSCs are currently being explored in clinics in treatments of various conditions, including graft versus host 
disease, cardiovascular diseases, and several autoimmune diseases [42].

\section{Key properties of CSCs}

CSCs share the same cellular and molecular mechanisms that regulate SSCs; however, CSCs lack the necessary control system to prevent uncontrolled proliferation [43]. While the specific origin of CSCs is still under debate, evidence suggests that they originate from stem cells that failed to control proliferation under abnormal circumstances $[44,45]$. Other proposed origins suggest that CSCs could arise from cell-cell fusion between cancer cells and adult stem cells, gene transfer between somatic and cancer cells, or mutations in stem cells [46]. In addition, transformation could occur during the process of tissue regeneration in response to inflammation, infection, toxin exposure, and/or metabolic processes which could cause mutations [47].

CSCs have been identified in several solid tumors based on the expression of certain CSC surface markers. Until now, CSCs have been identified by surface markers that are common between different cancer types: CD24, CD29, CD44 CD90, CD133, aldehyde dehydrogenase 1 (ALDH1), and epithelial-specific antigen (ESA) [48-50]. Depending on the type of tissue from which they originate, they can express a variety of markers for each type of CSCs. Most importantly, the expression of these markers can be used for specific therapeutic targeting of CSCs [51] (further discussed in later sections).

Evidence from a xenotransplantation experiment of human brain tumors into non-obese diabetic severe combined immunodeficiency (NOD/SCID) mouse brains did demonstrate the presence of CSCs in the tumor fraction responsible for tumor regeneration [52]. Other studies also report that certain types of cancers, such as hepatocellular carcinoma (HCC), can be derived from SSCs [53]. HSCs originate from self-renewing progenitors in the bone marrow where they mostly reside; however, they also can be found in peripheral blood. Clinical and genetic evidence suggest that certain types of leukemia are driven by genetic mutation in HSCs. These mutations give rise to leukemia stem cells, also called CSCs of the blood [54, 55]. Additionally, in a NOD/SCID murine model of leukemia, phenotypic differences between leukemia stem cells and HSCs were shown in separate studies [56, 57]. Recent efforts uncovered surface markers that are exclusive for AML stem cells such as CD123, TIM3, CD47, CD96, CLL-1, and IL-1 receptor accessory protein. On the other hand, AML stem cells rarely express CD90 and CD117 on their surface [58] and several studies have reported that CD123 was predominantly expressed in a subset of AML stem cells characterized by CD34+/CD38- phenotype [56]. These basic differences in the phenotype of
CSCs could be essential to providing new avenues for the development of targeted cancer therapeutics.

CSCs are commonly confused with cancer-initiating cells because of their stem cell-like properties, where both are characterized by elevated expression of the stem cell surface marker CD133 [59]. When cancerinitiating cells receive the first cancer-causing mutation, they are hypothesized to be different from SSCs; however, they show several similarities such as low proliferative rates, high self-renewal, and resistance to chemotherapy and radiation [60]. Currently, it is not clear whether CSCs originate from cancer-initiating cells or if both cell types have the same origin. However, both cells support tumor initiation and propagation.

\section{Environmental milieu and chronic inflammation support CSCs}

Cell microenvironment is fundamental for cell growth, fate, and interaction with other cells in response to a specific stimulus. Recent studies have confirmed that the microenvironment can support generation and growth of solid tumors [61], and it is possible that alterations in paracrine signals from niche cells could initiate or enhance tumor formation from SSCs. These signals function as a stimulus to induce activation, differentiation, proliferation, and/or cell death [62]. Moreover, these environmental stimuli are a part of a greater structure called "stem cell niche". This niche refers to a specific microenvironment inside a discrete anatomic location where SSCs are found in an undifferentiated and selfrenewable state [63]. These niches have been observed in different mammalian epithelial tissues, in the gastro intestinal tract, and in the neural and hematopoietic system where they regulate stem cell fate by directing cellcell interaction and secretion factors [64]. Soluble factors secreted from primary tumors can stimulate the recruitment of cells to the niche. Growth factors such as VEGF, TGF- $\beta$, and TNF- $\alpha$ have been identified as the major factors secreted from primary tumors which promote angiogenesis $[65,66]$.

Soluble factors released in the microenvironment strongly influence the growth of a primary tumor, where its growth is further enhanced by changes in the niche environment [64]. CSCs reside in these niches which are responsible for maintaining the self-renewal capacity and undifferentiated state of CSCs [67]. These niches maintain the main properties of CSCs by preserving their phenotypic plasticity, protecting the cells against the immune system and low nutrient availability, resisting oxidative stress, detoxifying drugs via ATP-binding cassette transporters, and promoting metastasis [68]. These niches also favor the recruitment of more cells to induce inflammation by secreting factors (cytokines and chemokines). The secreted factors facilitate the formation of 
secondary and tertiary tumors [69], where CSCs disseminate through the stroma into the bloodstream and induce metastasis [70].

Another important environmental factor driving tumor progression is chronic inflammation. This condition is hypothesized to be one of the principal factors in CSCs expansion and tumor dissemination [71]. This inflammatory response can be initiated by the activation of toll-like receptors (TLRs), stimulated by pathogen-associated-molecular patterns (PAMPs) of carcinogenic microbes or by products released from cancer cells. Consequently, nuclear factor kappa B (NF-kB) is activated inducing an inflammatory response that could increase self-renewal activity in cancer cells [72]. It was shown that in $\mathrm{CD} 44^{+} / \mathrm{MyD} 8^{+}$epithelial ovarian CSCs, the TLR2/MyD88/NF- $\mathrm{kB}$ signaling can support its growth and self-renewal by the upregulation of stemness-associated genes [73]. Another TLR that seems to promote the expression of stemness-associated genes is TRL3. For example, Jia et al. showed that poly(I:C) enhances stemness in cancer cells by the mutual activation of $\beta$-catenin and NF- $\mathrm{kB}$ signaling pathway. They demonstrated both in vitro and in vivo that breast CSCs, characterized by expression of CD44high/CD24-/low markers, possess stem cell-like properties and tumor-initiating capacity. They also established that TLR3 activation in breast cancer cells contributes to an enrichment of a subset of cells with the CSC phenotype [74].

Further evidence that supports the role of inflammation in cancer progression stems from observations that malignant tumors often develop at sites of chronic inflammation and tissue injury [75]. Chronic viral hepatitis [76], general gastric inflammation [77], gastritis caused by Helicobacter pylori [78], inflammatory bowel disease, and several other chronic inflammation conditions are also shown to increase the risk of cancer development [79], and the induction of CSCs [80]. Tumor stroma also contains activated fibroblasts, inflammatory cells, and nascent blood capillaries. The formation of such microenvironments facilitates induction of an inflammatory response that causes cell migration and epithelial cell proliferation. This results in tissue repair that can occasionally turn into uncontrolled cell proliferation and dissemination [81, 82]. O'Brien et al. showed that the ability of cancer cells to function as CSCs depends on how they respond to the self-renewal signals released in the environmental milieu [83]. It was suggested that changes in the environmental milieu can lead to reprogramming of SSCs turning them into cancer stem cells after prolonged inflammation, infection, exposure to toxins, or autoimmune diseases [84]. Some reports have shown that tumor environmental milieu provides the stimuli necessary for the transformation of SSCs by secreting TGF- $\beta$ [85]. This cytokine will enhance the transition from SSCs to CSCs by inducing zinc finger
E-box-binding homeobox1 (ZEB1) transcription factor expression. ZEB1 contributes to cancer dissemination and the activation of epithelial-mesenchymal transition (EMT), a process that has been linked to cancer metastasis. Additional evidence suggests that ZEB1 is responsible for the maintenance of CSC-like phenotypes [86, 87]. Another example of inflammatory conditions affecting CSC development is hepatocellular progenitor cancer cells (HcPCs), which have been observed following chronic inflammation in the liver. HcPCs show a similar transcriptomic profile to the SSCs in the liver but these cells do not generate tumors. However, under chronic inflammation, interleukin-6 (IL-6) secretion stimulates $\mathrm{HcPC}$ growth in vivo and facilitates tumor progression [88]. The role that chronic inflammation plays in the induction of different types of CSCs is still under investigation, but cytokines secreted by tumorassociated immune cells seem to activate the necessary pathways required by cancer cells to become cancer stem cell like.

\section{Immunoregulatory properties of SSCs and CSCs}

One important characteristic of SSCs is their ability to regulate the immune response during inflammatory conditions. The immune system is designed to recognize foreign antigens expressed on antigen presenting cells (APCs). This recognition leads to the activation of naïve $\mathrm{T}$ cells [89], which involves the specific recognition of a $\mathrm{T}$ cell receptor with a peptide bound to a major histocompatibility complex (MHC) class II [89]. Two signals are fundamental to ensure the appropriate activation: one is the interaction of MHC class II loaded peptide and T cell receptor (TCR), and the other signals are provided by costimulatory molecules CD80, CD86, CD40; adhesion molecules such as lymphocyte function-associated antigen 1 and intercellular adhesion molecule 1 . There are also negative co-stimulatory molecules that are responsible for $\mathrm{T}$ cell suppression [90]. These suppressive co-stimulatory molecules or negative regulators of $\mathrm{T}$ cell immune function molecules are programmed death ligand- 1 and cytotoxic T-lymphocyte associated antigen-4.

MSCs are weakly immunogenic and possess immunomodulatory properties toward natural killer cells, dendritic cells, neutrophils, B cells, and T cells [91], where the effect on T cells are the most studied. MSCs exert their immunoregulatory effects by inhibiting activated $\mathrm{T}$ cell proliferation as well as stimulating regulatory $\mathrm{T}$ cell (Treg) proliferation [91]. For example, MSCs decrease the T helper 1 (Th1) response [92, 93], but they can also induce a shift from Th2 to Th1 response under certain inflammatory conditions [94, 95], suggesting that MSCs can switch their phenotype to protect the body from disease in different situations. Mechanistic aspects of MSC-mediated suppression of T cells reveal three complementary mechanisms: (1) cell-cell contact interaction between MSCs and T cells, (2) secretion 
of soluble mediators, and (3) generation of Tregs (reviewed in [96]). Recognizing these properties opens a field for treatments that tackle immune response modulation. Preclinical animal models of large-organ transplant rejection, autoimmune diseases, and chronic inflammatory diseases showed that allogeneic MSCs induced a marked suppression of the host immune response [91]. Additionally, some clinical trials that used MSCs in patients with severe graftvs-host disease (GVHD) showed that the administration of MSCs resulted in an improvement in the clinical response [97]. It was also demonstrated that MSCs modulate GVHD by $\mathrm{CD}^{+}$and $\mathrm{CD} 8^{+} \mathrm{T}$ cell proliferation suppression, $\mathrm{B}$ cell suppression, Tregs induction, Th17 suppression, and the release of soluble immunomodulatory factors [98]. Similar positive effects of bone marrow MSCs have also been demonstrated in patients with acute respiratory distress syndrome (ARDS) [99, 100]. Besides these conditions, MSCs are widely used in clinical trials of spinal cord injuries, Sjögren's syndrome, rheumatoid artritis, lupus erytromatosis, amyotrophic lateral sclerosis, multiple sclerosis, and neuropathies.

As previously discussed, the immunoregulatory properties of MSCs are well studied; however, little is known about the potential immunological properties of CSCs. It is well known that the immune system plays an important role in attacking tumor cells [67] by detecting traits of malignant transformation by immune cells. Conversely, tumor cells can sometimes escape immune recognition, especially when progenitor cancer cells have already been established [101]. It has been shown that CSCs are more tumorigenic than regular cancer cells found in the solid tumor [102] and CSCs might evade the host immune response due to their phenotypic and functional properties, allowing them to endure and spread throughout the body. Tumor cells can evade the host immune response by different mechanisms, among them are the production of immunosuppressive factors, low expression of tumor antigens, lack of expression of human leukocyte antigens (HLAs), and costimulatory molecules [103]. Immunosuppressive factors are produced in the tumor microenvironment where other immune cells also participate by releasing soluble factors that further immunosuppress the environment [104]. The action of tumor-associated macrophages (TAM), an activated M2 polarized population, suppresses the inflammatory response and promotes tumor angiogenesis [105]. It was shown that TAM co-localized with $\mathrm{CD} 133^{+}$glioma cells increased the invasive capability of these cells by secreting TGF- $\beta 1$ [104]. Little is known about CSCs immune-regulatory properties but certainly they represent an important factor in the failure of cancer treatment. It was suggested that CSCs can escape natural killer (NK) cells recognition by entering into a latency stage and downregulating ULBP ligands that binds to and activates NK cells [106]. Additionally, CSC can evade cytotoxic T cells by downregulating MHC-I and upregulating the expression of PD-L1, resulting in host immunosuppression [107].

A study compared the immunological properties of CSCs-like cells $\left(\mathrm{CD} 44^{+}\right)$with tumor cells $\left(\mathrm{CD} 44^{-}\right)$and demonstrated that $\mathrm{CD} 44^{+}$cancer stem-like cells have an immunosuppressive phenotype. This effect was probed by the inhibition of activated $\mathrm{T}$ cell proliferation, the induction of Treg polarization, and the suppression of Th1, which leads to the dysfunction of effector $\mathrm{T}$ cell and cytotoxic $\mathrm{T}$ cells [103]. Another study showed that CSCs isolated from therapy-resistant tumors have pro-inflammatory tumorigenic properties; such CSCs can induce macrophage colony-stimulating factor production by activating interferon regulatory factor-5 (IRF-5) pathway [108]. This study also found that they could induce several pro-inflammatory cytokines and chemokines such as TNF- $\alpha$, IL-6, and IL-8, creating a tumorigenic microenvironment [108]. Recent studies also suggest that, in addition to secreted cytokines, other secreted factors also contribute to downregulation of the immune response. For example, extracellular vesiclemediated communication between tumor cells and immune cells may result in downregulation of the immune response to tumor cells [109]. $\mathrm{Bi}$ et al. accentuated the role of IRF-5 in regulating tumor infiltration and found that the loss of IRF-5 expression in human ductal carcinoma correlates with disease stage and contributes to metastasis [110]. Therefore, it appears that MSCs and CSCs share the same immune-regulatory properties. The difference is that MSCs use these properties in regeneration of damaged tissues and in immunomodulation, while CSCs use this property to endure in the tumor and evade the immune response. These characteristics also suggest that immune-suppression pathways could potentially be targeted for tumor clearance by immune response mediated mechanisms.

\section{Self-renewal activity and signaling pathways in CSCs}

Similar signaling pathways regulate the self-renewal activity in ESCs, SSCs, and CSCs. ESCs are pluripotent and can differentiate into any specialized cell in the body, while SSCs have more limited differentiation capacities [111]. ESCs can be maintained in culture for long periods of time without losing their undifferentiated state [112]. On the contrary, SSCs cultured in vitro differentiate rapidly, indicating that environmental and internal signals are fundamental for SSCs differentiation process and self-renewal $[113,114]$. It is suggested that internal signals directed by genetic and epigenetic processes, and external signals composed of secreted cytokines and growth factors can change the fate of SSCs [86]. The self-renewal activity of SSCs is highly regulated by different signaling pathways but this tight regulation is lost in CSCs. It has been shown that specific pathways such as Wnt/ $\beta$-catenin, Jack/Stat, TGF- $\beta$, Notch, and Sonic Hedgehog are deregulated in CSCs 
[115]. Instead, CSCs have the ability to use these selfrenewal pathways to drive tumor dissemination.

\section{Role of Wnt/ $\beta$-catenin pathway in CSCs}

The Wnt signaling pathway belongs to a family of secreted glycoproteins that have several functions, including regulating proliferation, differentiation, and patterning throughout embryonic development [116]. Other components of the Wnt pathway include molecules of the Wnt secretory machinery, Wnt co-receptors, new components of the $\beta$ catenin degradation machinery, and nuclear co-factors $[117,118]$. Mutations in Wnt genes or defects in their signaling pathway cause specific developmental defects during embryonic development leading to certain human diseases and cancer during adulthood [119-122]. Abnormal activation of the Wnt/ $\beta$-catenin pathway is one of the most frequent abnormalities present during tumorigenesis. Abnormal expression of Wnt ligand proteins has been observed in different types of tumors in osteosarcoma [123], hematological malignancies [124], breast cancer [125], and non-small cell lung cancer [126]. Malanchi et al. showed that $\beta$-catenin signaling is essential in maintaining CSC phenotype and its inhibition results in the loss of CSCs and total tumor regression indicating increased activation of $\beta$ catenin pathway in human squamous cell carcinoma [127]. Moreover, Wnt signaling has been shown to be deregulated in leukemic stem cells compared to somatic hematopoietic stem cells. These results were obtained from a genomewide expression analysis that compared the expression profile of highly enriched normal human HSCs and leukemic stem cells from patients with AML [128]. In AML, deregulated activation of the $\mathrm{Wnt} / \beta$-catenin pathway induces cell proliferation by turning on genes encoding oncoproteins and cell-cycle regulators [129]. Furthermore, Wnt5a pathways seem to be involved in the regulation of CSCs, as reviewed by Zhou et al. which showed that there is a complex cross-talk between Wnt5a and specific receptors that are expressed in ESCs and that may be expressed or activated in CSCs but not in SSCs [130].

STAT signaling deregulation is associated with CSCs induction Signal transducers and activators of transcription (STATs) involve tyrosine phosphorylation by Janus family tyrosine kinases (JAKs) that further allow STAT protein dimerization and nuclear translocation and, finally, expression of target genes [131]. Gene encoding of the STAT family is localized on different chromosomes: in chromosome 2 (STAT1 and STAT4), in chromosome 12 (STAT2 and STAT6), and in chromosome 17 (STAT3 and STAT 5A/B) [132]. JAK-STAT signaling pathway regulates somatic cell differentiation, proliferation, immune response, and apoptosis [133]. We previously discussed the role of JAK-STAT3 signaling pathway in promoting cancer through inflammation, obesity, stem cells, and pre- metastatic niche, and how the regulation of this pathway in tumors constitute an important target for therapeutics in the treatment of cancer [134]. We also found that STAT3 activation mediates the loss of androgen receptor expression, which promotes a stem-like cell phenotype in prostate cancer [135]. STAT signaling pathway has also been shown to regulate both stem cell-renewal and tumorigenesis, and abnormal activation of the STAT pathway induces cell transformation and oncogenesis of many cancer types [136, 137]. This deregulation of STAT pathway can cause the inhibition of differentiation pathways and instead induces stem cell self-renewal [138]. Moreover, it has been shown that STAT signaling plays a role in different stem cell niches in SSCs and CSCs. For example, STAT5 was shown to be activated in HSCs by the stem cell factors c-Kit and thrombopoietin, both fundamental factors for HSCs self-renewal [139]. STAT5 has also been observed to be constantly expressed in different hematological and non-hematological malignancies [139]. Hernandez-Vargas et al. suggested that a sub-population of sorted $\mathrm{CD} 44^{+} / \mathrm{CD} 24^{-}$, considered to be breast CSCs, constitutive activate JAK-STAT signaling pathway. Their data also support the concept that the expression of cancer stem-like pathways and the establishment and selfrenewal properties of cancer stem cells are coordinated by epigenetic mechanisms [140].

\section{TGF- $\beta$ pathway is involved in CSCs development and tumor progression}

The TGF- $\beta$ pathway is another important pathway involved in embryonic development, in adult tissue homeostasis, and in the regulation of stemness of CSCs [141]. TGF- $\beta$ signaling is initiated upon TGF- $\beta$ ligand interaction with type II and type I transmembrane serine/threonine kinase receptors on the cell surface which induces oligomerization of the receptor kinases and phosphorylation of the cytoplasmic signaling molecules Smad2 and Smad3 for the TGF- $\beta$ /activin pathway [142]. The activated Smad complexes are translocated into the nucleus together with other nuclear co-factors to regulate the transcription of target genes [142]. Interestingly, the loss of function of certain Smads is observed during tumorigenesis of pancreatic and colorectal cancers as well as other cancer types [142-144].. TGF- $\beta$ is mostly known for its role as hepatic pro-fibrogenic cytokine predominantly produced by activated mesenchymal cells upon chronic liver damage, suggesting that it also participates in tissue repair and maintenance in SSCs. TGF- $\beta$ induces Smad3-dependent nuclear accumulation of $\beta$-catenin in MSCs, and it was shown that TGF- $\beta$ signaling regulates the differentiation fate of MSCs [141]. Together with CSCs, TGF- $\beta$ participates in the initiation and development of various tumors, and in the acquisition of CSC-like properties [145]. 


\section{Notch and Sonic hedgehog signaling are important in CSCs development}

Notch signaling pathway also plays an important role during embryogenesis and cancer development [146]. Notch signaling is initiated by the interaction between a Notch ligand and a Notch receptor expressed on the surface of neighboring cells [147]. In mammals, the Notch pathway is formed by five canonical type I transmembrane ligands, including Delta-like ligands (DLLs), DLL1, DLL3, and DLL4; two Jagged proteins, Jagged1 and Jagged2; and four Notch transmembrane receptors, Notch1-4. This interaction triggers a two-step proteolytic cleavage of the receptor, mediated by an ADAM/ TACE (tumor necrosis factor alpha converting enzyme) metalloproteases. ADAM10 and ADAM17 interact with nuclear factors to regulate target gene expression that regulates cell differentiation $[115,146]$. This pathway is mainly involved in cell to cell communication, tissue differentiation, and self-renewal of stem cells. Notch pathway is deregulated in different cancers, and it is believed that Notch regulates the formation of cancer stem cells and the initiation of epithelial-mesenchymal transition phenotype [148].

Sonic hedgehog or hedgehog $(\mathrm{Hh})$ signaling pathway was initially discovered in the fruit fly as a regulator of body segmentation in 1980 . Hh signaling pathway forms one of the networks of major regulators of cell differentiation, proliferation, and cell polarity [149]. This pathway is a fundamental part of embryonic development [150]. It was shown that mutations generated in the Hedgehog pathway resulted in defective axial patterning, including cyclocephaly or holopronsencephaly, a cephalic disorder in which the Prosencephalon fails to develop in two hemispheres during embryogenesis [150]. Finally, it was discovered that alterations in Hh signaling pathway were also associated with cancer development [18]. Hh signaling has been shown to be crucial for the maintenance and expansion of CSCs. In other words, deregulation of $\mathrm{Hh}$ signaling has been linked with development of CSC formation and EMT development. This is seen in different types of tumors, especially in gastrointestinal cancers, leukemia, medulloblastoma, lung, and pancreatic cancer [151, 152]. Hh, like the Wnt signaling pathway, is one of the major regulators of cell differentiation and proliferation [153]. It has been shown that inhibition of $\mathrm{Hh}$ signaling depresses self-renewal of pancreatic cancer stem cells and reverses chemoresistance. Specifically, they found that PANC-1 tumorsphere has properties of stemness and differentiation and is highly tumorigenic [154]. All these pathways, in addition to their role in ESCs, SSCs, and CSCs self-renewal, have an important function as modulators of epithelial-mesenchymal transition initiation in cancer cells.

\section{Role of EMT and MET in CSC establishment and progression}

EMT is a phenomenon observed during normal embryonic development and tissue repair and is characterized by epithelial cell losing their cell polarity, cell to cell adhesion, and gaining migratory properties and eventually transforming into MSCs [155]. While epithelial cells are connected to each other by tight junctions, gap junctions, and desmosomes [156], MSCs do not form tight junctions and have a migratory role. Other important characteristics of epithelial cells are that they have cell polarity, that they have an apical and basal orientation, and that their morphology is basically symmetrical [156]. EMT and its opposite process called mesenchymal-toepithelial transition (MET) are important processes that occur during embryonic development $[157,158]$. Besides its role during embryonic development, it is known that EMT occurs in other physiological process such as wound healing, and in the development of organ fibrosis [159]. Unfortunately, the EMT process has shown to be involved in cancer initiation and metastatic progression (Fig. 2) [160]. Tumor metastasis is a complex process where initial tumor cells disseminate from their primary site to a distant site where they form secondary tumors. It is believed that EMT contributes to cancer metastasis by facilitating local invasion, intravasation, transport, extravasation (by allowing cells to move to nearby blood vessels), and finally colonization [161]. During cancer, EMT and MET show a dynamic relationship in which cells transiently undergo MET and in the next step undergo EMT to restart the metastatic process [162]. A study by Yamamoto et al. showed that spatiotemporally coordinated mutual regulation between EMT and MET could occur during metastasis [162, 163].

It is believed that the EMT process is an important regulator of cancer cell plasticity and multipotency, supported by the connection of EMT-stem cells occurring in both normal epithelial cells and cancer cells [164]. This theory argues that cancer cells do not create a de novo stem cell program, but instead they adopt stem cell properties by inducing EMT. This confers mesenchymal traits to cancer cells turning them into cancer stem cell-like cells with properties of high motility, invasiveness, and self-renewal capable of colonizing other tissues [164].

\section{EMT induction and regulation by stem cell pathways}

Epithelial to mesenchymal transition involves fundamental changes that involve several regulatory networks. EMT is triggered by the zinc finger protein SNAI1, Twist-related protein 1 (TWIST1), zinc finger E-boxbinding homeobox 1 (ZEB1), teratocarcinoma-derived growth factor-1 also known as Cripto-1, TGF- $\beta$, Wnt/ $\beta$ catenin, and Notch $[165,166]$. Most of these pathways downregulate the expression of E-cadherin, resulting in 


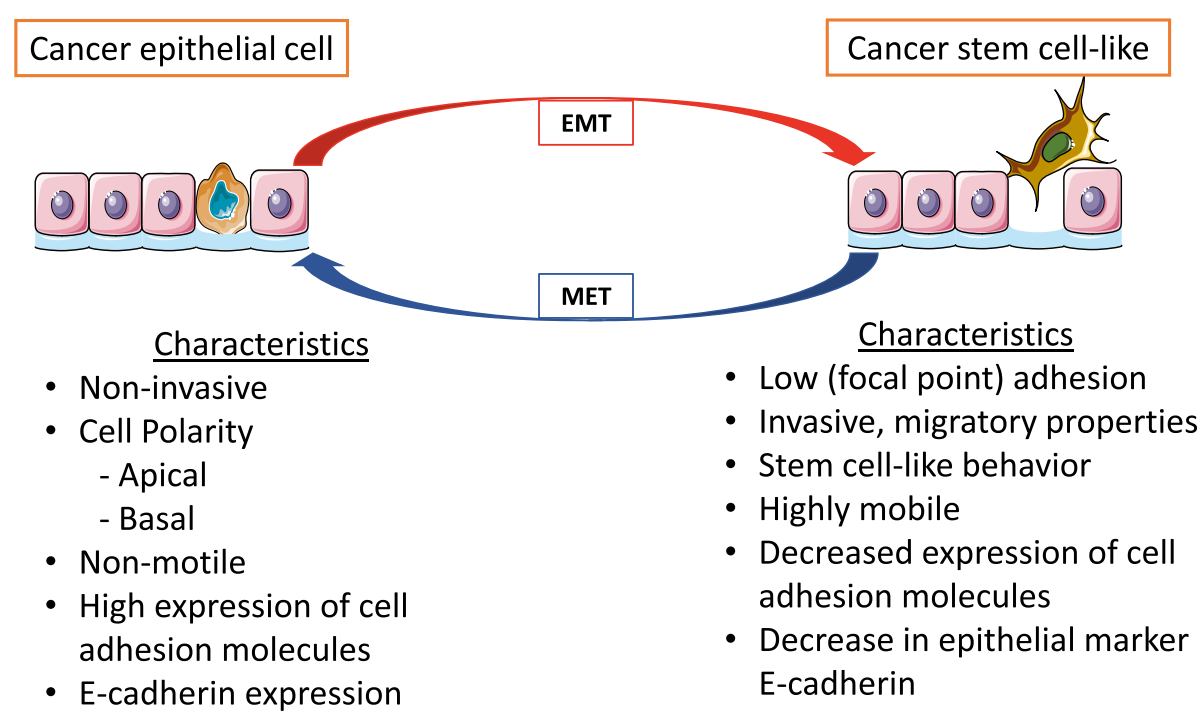

Fig. 2 Role of epithelial-mesenchymal transition (EMT) in inducing cancer cell-like phenotype. Cancer epithelial cells can undergo EMT to induce a cancer stem cell-like phenotype that expresses characteristics of mesenchymal stem cells. They can also revert back, using a process called mesenchymal epithelial transition (MET) in which they reacquire epithelial cell characteristics. These processes contribute to cancer cells invasive capacities and new cancer initiation

the loss of E-cadherin-dependent intracellular epithelial junctional complexes [158]. Snail, a family of zinc finger transcription repressors, is considered a key inducer of EMT but also plays an important role in cell survival, immune regulation, and stem cell biology [167]. Snail together with ZEB1 represses E-cadherin and simultaneously represses other junction proteins transcription factors such as claudins and desmosomes [160]. Additionally, ZEB1 was shown to be an important factor regulating cell plasticity and the induction of metastasis. On the contrary, ZEB1 depletion suppresses stemness and colonization in tumor cells [168]. Zhou et al. demonstrated that Snail contributes to the maintenance of stem cell-like phenotype in human pancreatic cancer by using a murine xenograft model of Snail knockdown [169]. They also showed that Snail knockdown led to a reduced number of tumor-bearing mice and a reduced average size of tumors that highly expressed E-cadherin and low expression of Oct4, a common transcription factor in stem cells, indicating that Snail is required in the preservation of the stem cell-like phenotype of cancer cells in pancreatic cancer [169]. Additionally, it has been shown that Snail-induced EMT is involved in promoting cancer stem cell-like properties in head and neck cancers [170]. Another important transcription factor involved in cell lineage fate and differentiation is TWIST1 also known as class A basic helix-loop-helix protein 38 transcription factor [171]. TWIST1 seems to be an important factor that contributes in tumor initiation by conferring cancer cell with stem-like properties. TWIS $\mathrm{T} 1$ is also a key player in the induction of EMT by promoting invadopodia-mediated extracellular matrix degradation [171].

Notch, TGF- $\beta$, and Wnt/ $\beta$-catenin signaling are known to participate in stem cells self-renewal pathways and have been proven to be involved in the regulation of CSCs and the initiation of EMT. All these pathways seem to be interconnected, as in the case of Notch and TGF- $\beta$ pathway. These two pathways aid in the EMT cross-talk with different transcription and growth factors such as Snail, Slug, and ZEB1 [172]. An in vitro study showed that the overexpression of Notch-1 increases the expression of Snail in immortalized endothelial cells and causes Snail to bind to the E-cadherin promoter region, resulting in E-cadherin gene repression [173]. Moreover, Notch1 increases TGF- $\beta /$ Smad signaling by upregulating the expression of TGF- $\beta$ and TGF- $\beta$ type 1 receptor, supporting the role of TGF- $\beta$ in the induction of EMT and survival of CSCs. The stimulation of TGF- $\beta$ receptors leads to the expression of the mesenchymal genes, such as vimentin, in addition to inducing ZEB1 [174]. Wnt signaling pathway mediates the initiation EMT process by the maintenance of mesenchymal state and stem cell properties promoting the stabilization of cytoplasmic $\beta$-catenin. Taken together, there is a reciprocal regulatory loop between the different pathways that cooperatively regulate EMT and is also associated with self-renewal activity in cancer stem-like cells or CSCs.

\section{Regulation of EMT by microRNAs}

MicroRNAs (miRNAs) are molecules consisting of approximately 21-25 nucleotides. They post-transcriptionally 
regulate gene expression to maintain biological homeostasis and regulate immune response [175-177]. Even though miRNAs seem to have an important role in self-renewal of SSCs, they also appear to play an important role in EMT regulation and CSCs initiation [178]. Some experiments using murine embryonic stem cells have shown that a knockout of DGCR8 and Dicer1, two major components of the miRNA silencing complex, causes a defect in stem cell differentiation [175-177]. According to Chakraborty et al., there are six major factors that are required for pluripotency maintenance, Nanog, Sox2, Oct4, KLF4, Lin28, and c-Myc [179, 180].. MiRNA-296, miRNA-470, miRNA-134, and miRNA181a were postulated to be potential targets for these factors and to inhibit stem cells self-renewal [181].

Besides its role in self-renewal, miRNAs also play an important role in different aspects of tumor progression, cancer cell invasion, metastasis, and EMT [182]. miRNA dysregulation has been shown in different types of cancers [183], such as breast, prostate, lung, and gastrointestinal cancers [184-186]. EMT is a complex process that is regulated by several signaling pathways in which miRNAs could potentially regulate directly by binding and suppressing EMT transcription factors, or indirectly by binding to an inhibitor of EMT. For example, miRNA-200 family, including miRNA-200b, miRNA200c, and miRNA-141, are some of the most important regulators of EMT [187]. It was shown that miRNA-200 targets ZEB1 and ZEB2 (E-cadherin repressor) and inhibits EMT progression [188]. The ectopic expression miR-200 caused the upregulation of E-cadherin in cancer cell lines and reduced their motility, while its inhibition reduced E-cadherin and vimentin expression, and induced EMT [187]. Other studies also showed that downregulation of miRNA-200 induced an increase in EMT in normal breast cells as well as in CSCs [148]. miR-21 downregulation in breast cancer cells caused a reversal of EMT and a decline in CSC numbers [148]. Additionally, other miRNAs that bind to transcription factors involved in EMT are miRNA-30, miRNA-34, and miRNA-203, blocking EMT induction. Taube et al. showed that epigenetic silencing of microRNA-203 is necessary for the induction of EMT and to obtain cancer stem cell properties. They also suggested that restoring miRNA-203 expression levels could inhibit metastasis [189]. On the other hand, there are other miRNAs that promote EMT. For example, miRNA-9 binds and suppresses E-cadherin, while the expression of miRNA-424 was showed to be linked to EMT induction in prostate cancer.

\section{Therapeutic strategies to target CSCs}

Targeting cell surface markers commonly expressed in CSCs A potential breakthrough in targeting CSCs could be achieved through targeting the differences in surface expression markers between SSCs and CSCs. Even though CSCs from different tissues have been characterized according to their phenotypic differences, there is still no definitive marker that only targets a specific population of CSCs. Currently, the identification and isolation of CSCs continue to be a challenge for therapeutic development; however, certain markers have been shown to be highly expressed among several different CSCs. Targeting human surface expression markers with monoclonal antibodies has shown to be a clinically and commercially established therapy. In CSCs, a combination of several markers could be the best approach for specific targeting of CSCs; for example, in breast cancer, the most highly expressed CSC markers include CD133, CD44, and aldehyde dehydrogenase (ALDH) [190]. CD133 (prominin-1) is expressed on CSCs in multiple tumors, and high expression of this marker has been associated with poor cancer prognosis, making this molecule a good target candidate [191]. CD44, a glycosylated type-1 transmembrane glycoprotein, is involved in cell to cell interactions, cell proliferation and cell migration, among the most widely used CSC markers, it is associated with increased potential for tumor initiation and progression [192]. Jin et al. showed that targeting CD44 with neutralizing antibodies inhibited tumor proliferation by eradicating human AML stem cells [193]. Both CD133 and CD44 have been identified on CSCs in breast, brain, colon, lung, prostate, liver, and gastric cancers, which makes these markers a potential target for neutralizing antibodies, antibody-mediated cancer stem cell therapies, or by engineering exosomes expressing these markers for drug delivery.

ALDH is an enzyme that catalyzes the oxidation of aldehydes to carboxylic acids to protect cells from oxidative stress. ALDH has been shown to be important for the maintenance of normal HSCs, and it is also commonly used as a marker to differentiate CSCs from different cancers [194]. Specifically, ALDH-1A1 subtype is frequently expressed in tumor-initiating cells or CSCs in several malignancies. Visus et al. generated ALDH-1A1 $1_{88-96}$ peptide-specific $\mathrm{T}$ cells for immune-targeting ALDH-1A1 expressing CSCs resulting in specific $\mathrm{T}$ cell targeting that controlled tumor growth and metastasis [195].

As shown in Table 1, several CSC markers for different types of cancers have been identified, and with the appropriate technology, it is possible to focus on a subset of these specific markers that are highly expressed in these populations and in conjunction with other therapeutic strategies to target these specific CSC populations. A monoclonal antibody targeting CSC marker CD44 has been evaluated in two clinical trials (www.clinicaltrials. gov) in both solid and hematologic malignancies either alone or in combination with cytarabine, but the results of these studies are currently unknown [209, 210]. Similarly, several clinical trials were initiated recently that will test clinical utility of an antibody termed Tagraxofusp (SL401) which targets CSC marker CD123 in patients diagnosed with hematologic malignancies [211]. 
Table 1 CSC markers from different types of cancers. Compilation of the most common CSC markers (in bold) identified from different types of cancers (references in brackets)

\begin{tabular}{|c|c|}
\hline $\begin{array}{l}\text { Tumor } \\
\text { type }\end{array}$ & Markers \\
\hline Leukemia & $\begin{array}{l}\text { CD34 }^{+}[191,196-198] ; \text { CD38 }^{-} \text {[191, 197, 198]; CD47 } \\
\text { CCL-1 [191]; CD96 }{ }^{+}[36,191] ; \text { CD90 }^{-}[198] ; \text { CD117 }^{-}[198] ; \\
\text { CD133 }\end{array}$ \\
\hline Breast & $\begin{array}{l}\text { CD34 }^{+}[200] ; \text { CD24 }^{\text {low }}[36,48,191,197] ; \text { ALDH1 }^{+}[198] ; \\
\text { CD29 } \\
\text { CD59 } \\
\text { (201]; } \text { Bmi-1 }^{+}[202]\end{array}$ \\
\hline Pancreatic & $\begin{array}{l}\text { ESA }^{+}[48,191] ; \text { CD} 4^{+}[48,191,198] ; \mathbf{C D}^{+} 4^{+}[48,191,198] \\
\text { CD133 }^{+}[36,48,198]\end{array}$ \\
\hline Lung & 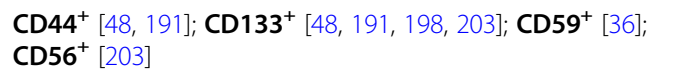 \\
\hline Liver & $\begin{array}{l}\operatorname{ESA}^{+}[191] ; \mathrm{CD}^{2} 33^{+}[48,191,198] ; \mathrm{CD}^{+}[191,198] ; \\
\mathrm{CD}^{+}{ }^{+}[48,191] ; \mathrm{CD}^{+} \mathbf{6}^{+}[48]\end{array}$ \\
\hline Gastric & $\mathrm{CD}^{133^{+}}[204] ; \mathrm{CD}^{+} 4^{+}[48] ; \mathrm{CD}^{+} 4^{+}[48,191]$ \\
\hline Colorectal & $\begin{array}{l}\mathrm{ESA}^{+}[191] ; \mathbf{C D}^{2} 3^{+}[36,48,191,198,205] ; \mathbf{C D}^{+} \mathbf{6 6}^{+} \\
{[48,191,198] ; \mathbf{C D}^{+}[48,191,198] ; \mathbf{C D}^{+} 4^{+}[48,191,198]}\end{array}$ \\
\hline Prostate & $\begin{array}{l}\text { Integrin a2ß1 [48]; CD44 }{ }^{+}[48,198] ; \text { CD133 }^{+}[48,198] ; \\
\text { Bmi-1 }[206]\end{array}$ \\
\hline Melanoma & $\mathrm{CD} 4^{+} / \mathrm{CD} 31^{+}[200] ; \mathrm{CD}^{+} \mathbf{0}^{+}[198] ; \mathrm{CD}^{+}{ }^{+}[207]$ \\
\hline Ovarian & $\begin{array}{l}\text { CD44 }^{+}[48,197,208] ; \mathbf{C D}_{117^{+}}[48,197,208] ; \text { CD133 }^{+} \\
{[48,208] ; \mathbf{C D} 24^{+}[48]}\end{array}$ \\
\hline
\end{tabular}

\section{Targeting CSCs by blocking their stem cell niche and} signaling pathways

The CSC microenvironment has been shown to be crucial for cancer initiation and tumor growth. It is not novel to try to target factors that potentiate tumor growth and dissemination as a therapeutic strategy; however, the problem is that these CSCs niches are enclosed and provide limited accessibility for most therapeutic antibodies or neutralizing cytokines. The use of exosomes in cancer therapy has gained more attention lately [212]. Exosomes are small intracellular membrane-based vesicles involved in the delivery by endocytosis or membrane fusion of molecules, antibodies, or drugs [213]. Exosomes expressing unique surface markers could be used to deliver drugs or molecules to a specific CSCs population to kill these cells [67]. Targeting specific factors that contribute to CSCs self-renewal and CSC proliferation by neutralizing those factors intracellularly or affecting different parts of the Hh, TGF- $\beta$, and Wnt pathway in several types of malignances is another approach to control CSCs [214]. Glasdegib is a small molecule which inhibits sonic hedgehog receptor smoothened and was recently approved by FDA in combination with low-dose cytarabine for newly diagnosed acute myeloid leukemia in patients with co-morbidities [215].

CSC microenvironment promote an immunosuppressive state and do not allow for a proper immune response, suggesting that one alternative approach to target this microenvironment is to blocking the action of myeloid suppressor cells action and targeting cellular receptors involved in immunomodulation, like PD1/PDL-1 [194]. For example, targeting VEGF-A with the humanized recombinant monoclonal antibody, bevacizumab. This drug inhibits the angiogenesis process by slowing down the growth of new blood vessels and disrupting the CSCs niche. It has already been shown in a glioblastoma murine model that treatment with bevacizumab depletes vasculature to the CSC microenvironment and drastically reduces the number of glioblastoma stem cells [216]. Fresolimumab, a monoclonal antibody that binds to all isoforms of TGF $\beta$ and thus modulates tumor microenvironment, has been tested in clinics in combination with focal irradiation for the treatment of metastatic breast cancers. This therapeutic combination was well tolerated and the subjects who received higher dose of the antibody had favorable antitumor responses and experienced longer median overall survival than the lower dose group [217].

Another way to block and reprogram CSCs is by using miRNAs. This has been shown by the use of exosomes to deliver specific miRNAs that block or arrest key CSCs signaling pathways [218]. SSCs express a unique set of miRNAs that maintain self-renewal, promote differentiation, and maturation. However, in CSCs, these miRNAs are deregulated. For example, the overexpression of miRNA-124 and miRNA-137 in human glioblastomaderived cancer stem cells resulted in the loss of selfrenewal and oncogenic capacity [219]. Han et al. also showed that blockage of miR-21 reverses EMT and CSC phenotype, suggesting that miRNA-21 has a role in CSC maintenance and this molecule could be targeted in future therapies [220]. No clinical trials utilizing such strategy are currently registered at clinicaltrials.gov but a number of promising pre-clinical studies have been published (reviewed in [221]).

\section{Concluding remarks}

One of the major reasons for the failure of conventional cancer therapies is the presence of CSCs. Unfortunately, most drugs used in cancer therapy exert their effect by killing fast proliferating cancer cells, with the side effect of targeting fast proliferating normal cells. In addition to the severe side effects of traditional cancer therapies, drug therapy resistance and the failure in achieving long-term cancer remission are steering scientists into the research of developing targeted treatments. The discovery of a sub-population of tumor cells that have selfrenewal and multipotent properties, now called cancer cell initiators or CSCs, opened new opportunities for research in the field of personalized cancer therapy. Understanding of the molecular and cellular mechanisms of CSCs is the best approach to efficiently target CSCs without affecting normal cells or SSCs (Fig. 3). 


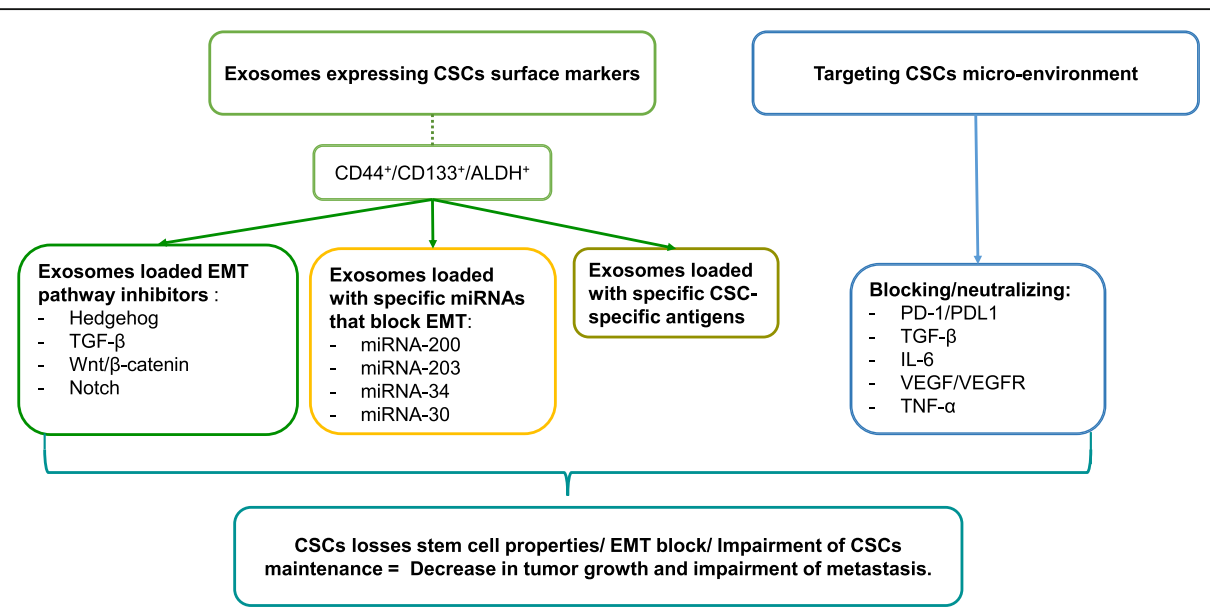

Fig. 3 Potential therapeutic strategies to target CSCS. Specific CSC targeting could be achieved by creating exosomes that display CSC markers which can be used to deliver important CSC pathway inhibitors or to deliver miRNAs that block the EMT pathway. Alternatively, it is also possible to target CSCs by blocking their microenvironment preventing the formation of new CSCs

The major pathways involved in CSCs are TGF-beta, Wnt, Hedgehog, and Notch, most of which are interconnected and participate not only in self-renewal properties but also in EMT initiation, an important factor in cancer initiation and metastasis. Therefore, targeting multiple mechanisms involved in growth and maintenance of CSCs is definitively the best path toward a safe and more effective cancer therapy.

\section{Abbreviations}

CSCs: Cancer stem cells; SSCs: Somatic stem cells; ESCs: Embryonic stem cells; MSCs: Mesenchymal stromal cells; AML: Acute myelogenous leukemia; CD: Cluster of differentiation; ALDH1: Aldehyde dehydrogenase 1; ESA: Epithelial-specific antigen; NOD/SCID: Non-obese diabetic severe combined immunodeficiency; PAMPs: Pathogen-associated-molecular patterns; NF-kB: Nuclear factor kappa B; TLRs: Toll-like receptors; ZEB1: Zinc finger E-box-binding homeobox1; EMT: Epithelial-mesenchymal transition; MET: Mesenchymal-to-epithelial transition; Treg: Regulatory T cell; GVHD: Graft-vs-host disease; ARDS: Acute respiratory distress syndrome; HLAs: Human leukocyte antigens; TAM: Tumor-associated macrophages; STATs: Signal transducers and activators of transcription; IRF-5: Interferon regulatory factor-5; NK: Natural killer; MHC: Major histocompatibility complex; JAKs: Janus family tyrosine kinases; DLLs: Delta-like ligands; Hh: Sonic hedgehog or hedgehog; TWIST1: Twist-related protein 1; miRNAs: MicroRNAs; ALDH: Aldehyde dehydrogenase

\section{Acknowledgements}

This research was supported by funding from Nova Southeastern University provided to The Cell Therapy Institute.

\section{Authors' contributions}

F.R.: wrote the manuscript. H.N.: wrote the manuscript. R.J.: edited the manuscript and provided financial support. V.B.: wrote and edited the manuscript. K-H.G.: conception and edited the manuscript. The authors read and approved the final manuscript.

\section{Availability of data and materials}

The data materials supporting the current study are included within the article.

Ethics approval and consent to participate Not applicable.
Consent for publication

All the authors declare that they consent for publication of this article.

\section{Competing interests}

The authors declare no conflict of interest.

\section{Author details}

${ }^{1}$ NSU Cell Therapy Institute, Nova Southeastern University, 3301 College Ave, 3200 South University Drive, Fort Lauderdale, FL 33328, USA. ${ }^{2}$ Department of Molecular Medicine and Surgery, Karolinska Institutet, Stockholm, Sweden. ${ }^{3}$ Department of Surgical Sciences, Division of Cardiothoracic Surgery and Anaesthesiology, Uppsala University, Akademiska University Hospital, Akademiska sjukhuset, ingång 50, 4 tr, 75185 Uppsala, Sweden.

Received: 9 July 2020 Accepted: 5 November 2020

Published online: 18 November 2020

\section{References}

1. Trichopoulos D, Adami HO. Introduction: progress and enigmas in cancer epidemiology. Semin Cancer Biol. 1998;8(4):215-7.

2. Pietras A. Cancer stem cells in tumor heterogeneity. Adv Cancer Res. 2011; 112:255-81.

3. Reuter S, Gupta SC, Chaturvedi MM, Aggarwal BB. Oxidative stress, inflammation, and cancer: how are they linked? Free Radic Biol Med. 2010; 49(11):1603-16.

4. Blanpain C. Tracing the cellular origin of cancer. Nat Cell Biol. 2013;15(2): 126-34.

5. Klein CA. Parallel progression of primary tumours and metastases. Nat Rev Cancer. 2009;9(4):302-12

6. Sadikovic B, Al-Romaih K, Squire JA, Zielenska M. Cause and consequences of genetic and epigenetic alterations in human cancer. Curr Genomics. 2008;9(6):394-408

7. Malanchi I, Santamaria-Martinez A, Susanto E, Peng H, Lehr HA, Delaloye JF, Huelsken J. Interactions between cancer stem cells and their niche govern metastatic colonization. Nature. 2011;481(7379):85-9.

8. Ludwig JA, Weinstein JN. Biomarkers in cancer staging, prognosis and treatment selection. Nat Rev Cancer. 2005;5(11):845-56.

9. Cooper GM. The cell: a molecular approach, 2nd edn. Washington, D.C.: Sinauer Associates; 2000.

10. Jamal-Hanjani M, Quezada SA, Larkin J, Swanton C. Translational implications of tumor heterogeneity. Clin Cancer Res. 2015;21(6):1258-66.

11. Pattabiraman DR, Weinberg RA. Tackling the cancer stem cells - what challenges do they pose? Nat Rev Drug Discov. 2014;13(7):497-512.

12. Tang DG. Understanding cancer stem cell heterogeneity and plasticity. Cell Res. 2012;22(3):457-72. 
13. Blokzijl F, de Ligt J, Jager M, Sasselli V, Roerink S, Sasaki N, Huch M, Boymans $S$, Kuijk E, Prins $P$, et al. Tissue-specific mutation accumulation in human adult stem cells during life. Nature. 2016;538(7624):260-4.

14. Adams PD, Jasper $\mathrm{H}$, Rudolph KL. Aging-induced stem cell mutations as drivers for disease and cancer. Cell Stem Cell. 2015;16(6):601-12.

15. Marsh JC, Durivage HJ, Davis C, O'Hollaren K, Pasquale DN, Simonich SA, Voynick IM, Bertino JR. Phase II study of pulse 5-fluoro-2'-deoxyuridine and leucovorin in advanced colorectal cancer patients previously treated with chemotherapy. Am J Clin Oncol. 1992;15(2):115-8.

16. Afify SM, Seno M. Conversion of stem cells to cancer stem cells: undercurrent of cancer initiation. Cancers (Basel). 2019;11(3):345.

17. Bonnet D, Dick JE. Human acute myeloid leukemia is organized as a hierarchy that originates from a primitive hematopoietic cell. Nat Med. 1997;3(7):730-7.

18. Rajasekhar VK. Cancer stem cells. Hoboken: Wiley; 2014

19. Baker M. Cancer stem cells, becoming common; 2008.

20. Hayat MA. Stem cells and cancer stem cells : therapeutic applications in disease and injury. Dordrecht: Springer; 2012.

21. Bagley RG, Teicher BA. Stem cells and cancer. Totowa: Humana; 2009.

22. Ebben JD, Treisman DM, Zorniak M, Kutty RG, Clark PA, Kuo JS. The cancer stem cell paradigm: a new understanding of tumor development and treatment. Expert Opin Ther Targets. 2010;14(6):621-32.

23. Scadden DT. Cancer stem cells refined. Nat Immunol. 2004;5(7):701-3.

24. Goodell MA, Nguyen H, Shroyer N. Somatic stem cell heterogeneity: diversity in the blood, skin and intestinal stem cell compartments. Nat Rev Mol Cell Biol. 2015;16(5):299-309.

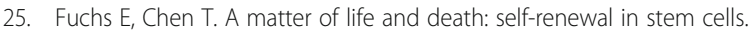
EMBO Rep. 2013;14(1):39-48.

26. Wang Z, Ema H. Mechanisms of self-renewal in hematopoietic stem cells. Int J Hematol. 2016;103(5):498-509.

27. Lobo NA, Shimono Y, Qian D, Clarke MF. The biology of cancer stem cells. Annu Rev Cell Dev Biol. 2007;23:675-99.

28. Mizuno H. Adipose-derived stem cells for tissue repair and regeneration: ten years of research and a literature review. J Nippon Med Sch. 2009;76(2):56-66.

29. Maxson S, Lopez EA, Yoo D, Danilkovitch-Miagkova A, Leroux MA. Concise review: role of mesenchymal stem cells in wound repair. Stem Cells Transl Med. 2012;1(2):142-9.

30. Ferraro F, Celso CL, Scadden D. Adult stem cels and their niches. Adv Exp Med Biol. 2010;695:155-68.

31. Voog J, Jones DL. Stem cells and the niche: a dynamic duo. Cell Stem Cell. 2010;6(2):103-15.

32. Mardanpour P, Guan K, Nolte J, Lee JH, Hasenfuss G, Engel W, Nayernia K. Potency of germ cells and its relevance for regenerative medicine. J Anat. 2008;213(1):26-9.

33. De Los AA, Ferrari F, Xi R, Fujiwara Y, Benvenisty N, Deng H, Hochedlinger K, Jaenisch R, Lee S, Leitch HG, et al. Hallmarks of pluripotency. Nature. 2015; 525(7570):469-78.

34. Sohni A, Verfaillie CM. Multipotent adult progenitor cells. Best Pract Res Clin Haematol. 2011;24(1):3-11.

35. Takahashi K, Yamanaka S. A decade of transcription factor-mediated reprogramming to pluripotency. Nat Rev Mol Cell Biol. 2016;17(3):183-93.

36. Zhao W, Ji X, Zhang F, Li L, Ma L. Embryonic stem cell markers. Molecules. 2012;17(6):6196-236

37. Wagers AJ, Weissman IL. Plasticity of adult stem cells. Cell. 2004;116(5): 639-48.

38. Calvi LM, Link DC. The hematopoietic stem cell niche in homeostasis and disease. Blood. 2015;126(22):2443-51.

39. Kauts ML, Vink CS, Dzierzak E. Hematopoietic (stem) cell development - how divergent are the roads taken? FEBS Lett. 2016;590(22):3975-86.

40. Fajardo-Orduna GR, Mayani H, Montesinos JJ. Hematopoietic support capacity of mesenchymal stem cells: biology and clinical potential. Arch Med Res. 2015;46(8):589-96.

41. Horwitz EM, Le Blanc K, Dominici M, Mueller I, Slaper-Cortenbach I, Marini FC, Deans RJ, Krause DS, Keating A, International Society for Cellular T. Clarification of the nomenclature for MSC: The International Society for Cellular Therapy position statement. Cytotherapy. 2005;7(5):393-5.

42. Wu X, Jiang J, Gu Z, Zhang J, Chen Y, Liu X. Mesenchymal stromal cell therapies: immunomodulatory properties and clinical progress. Stem Cell Res Ther. 2020;11(1):345.

43. Spillane JB, Henderson MA. Cancer stem cells: a review. ANZ J Surg. 2007; 77(6):464-8
44. Rycaj K, Tang DG. Cell-of-origin of cancer versus cancer stem cells: assays and interpretations. Cancer Res. 2015;75(19):4003-11.

45. Shah M, Allegrucci C. Stem cell plasticity in development and cancer: epigenetic origin of cancer stem cells. Subcell Biochem. 2013;61:545-65.

46. Nimmakayala RK, Batra SK, Ponnusamy MP. Unraveling the journey of cancer stem cells from origin to metastasis. Biochim Biophys Acta Rev Cancer. 2019;1871(1):50-63.

47. Walcher L, Kistenmacher AK, Suo H, Kitte R, Dluczek S, Strauss A, Blaudszun AR, Yevsa T, Fricke S, Kossatz-Boehlert U. Cancer stem cells-origins and biomarkers: perspectives for targeted personalized therapies. Front Immunol. 2020;11:1280.

48. Xia P. Surface markers of cancer stem cells in solid tumors. Curr Stem Cell Res Ther. 2014;9(2):102-11.

49. Ajani JA, Song S, Hochster HS, Steinberg IB. Cancer stem cells: the promise and the potential. Semin Oncol. 2015;42(Suppl 1):S3-17.

50. Ding B, Liu P, Liu W, Sun P, Wang CL. Emerging roles of Kruppel-like factor 4 in cancer and cancer stem cells. Asian Pac J Cancer Prev. 2015;16(9):3629-33.

51. Burgess R, Huang RP. Cancer stem cell biomarker discovery using antibody array technology. Adv Clin Chem. 2016;73:109-25.

52. Singh SK, Hawkins C, Clarke ID, Squire JA, Bayani J, Hide T, Henkelman RM, Cusimano MD, Dirks PB. Identification of human brain tumour initiating cells. Nature. 2004;432(7015):396-401.

53. Dang HT, Budhu A, Wang XW. The origin of cancer stem cells. J Hepatol. 2014;60(6):1304-5.

54. Bowman RL, Busque L, Levine RL. Clonal hematopoiesis and evolution to hematopoietic malignancies. Cell Stem Cell. 2018;22(2):157-70.

55. Noetzli $\sqcup$, French SL, Machlus KR. New insights into the differentiation of megakaryocytes from hematopoietic progenitors. Arterioscler Thromb Vasc Biol. 2019;39(7):1288-300.

56. Jordan CT, Upchurch D, Szilvassy SJ, Guzman ML, Howard DS, Pettigrew AL, Meyerrose T, Rossi R, Grimes B, Rizzieri DA, et al. The interleukin-3 receptor alpha chain is a unique marker for human acute myelogenous leukemia stem cells. Leukemia. 2000;14(10):1777-84.

57. Blair A, Hogge DE, Ailles LE, Lansdorp PM, Sutherland HJ. Lack of expression of Thy-1 (CD90) on acute myeloid leukemia cells with long-term proliferative ability in vitro and in vivo. Blood. 1997;89(9):3104-12.

58. Wang $X$, Huang S, Chen JL. Understanding of leukemic stem cells and their clinical implications. Mol Cancer. 2017;16(1):2.

59. Neuzil J, Stantic M, Zobalova R, Chladova J, Wang X, Prochazka L, Dong L, Andera L, Ralph SJ. Tumour-initiating cells vs. cancer 'stem' cells and CD133: what's in the name? Biochem Biophys Res Commun. 2007;355(4):855-9.

60. Bu Y, Cao D. The origin of cancer stem cells. Front Biosci (Schol Ed). 2012;4: 819-30.

61. Shiao SL, Ganesan AP, Rugo HS, Coussens LM. Immune microenvironments in solid tumors: new targets for therapy. Genes Dev. 2011;25(24):2559-72.

62. White AC, Lowry WE. Refining the role for adult stem cells as cancer cells of origin. Trends Cell Biol. 2015;25(1):11-20.

63. Jones DL, Wagers AJ. No place like home: anatomy and function of the stem cell niche. Nat Rev Mol Cell Biol. 2008;9(1):11-21.

64. Plaks $V$, Kong N, Werb Z. The cancer stem cell niche: how essential is the niche in regulating stemness of tumor cells? Cell Stem Cell. 2015; 16(3):225-38

65. Ucuzian AA, Gassman AA, East AT, Greisler HP. Molecular mediators of angiogenesis. J Burn Care Res. 2010;31(1):158-75.

66. Oskarsson T, Batlle E, Massague J. Metastatic stem cells: sources, niches, and vital pathways. Cell Stem Cell. 2014;14(3):306-21.

67. Ye J, Wu D, Wu P, Chen Z, Huang J. The cancer stem cell niche: cross talk between cancer stem cells and their microenvironment. Tumour Biol. 2014; 35(5):3945-51.

68. Fletcher Jl, Haber M, Henderson MJ, Norris MD. ABC transporters in cancer: more than just drug efflux pumps. Nat Rev Cancer. 2010;10(2):147-56.

69. Wels J, Kaplan RN, Rafii S, Lyden D. Migratory neighbors and distant invaders: tumor-associated niche cells. Genes Dev. 2008;22(5):559-74.

70. Fiori ME, Villanova L, De Maria R. Cancer stem cells: at the forefront of personalized medicine and immunotherapy. Curr Opin Pharmacol. 2017; 35:1-11.

71. Tanno T, Matsui W. Development and maintenance of cancer stem cells under chronic inflammation. J Nippon Med Sch. 2011;78(3):138-45.

72. Yeh DW, Huang LR, Chen YW, Huang CF, Chuang TH. Interplay between inflammation and stemness in cancer cells: the role of toll-like receptor signaling. J Immunol Res. 2016;2016:4368101. 
73. Chefetz I, Alvero AB, Holmberg JC, Lebowitz N, Craveiro V, Yang-Hartwich Y, Yin G, Squillace L, Gurrea Soteras M, Aldo P, et al. TLR2 enhances ovarian cancer stem cell self-renewal and promotes tumor repair and recurrence. Cell Cycle. 2013;12(3):511-21.

74. Jia D, Yang W, Li L, Liu H, Tan Y, Ooi S, Chi L, Filion LG, Figeys D, Wang L. Beta-catenin and NF-kappaB co-activation triggered by TLR3 stimulation facilitates stem cell-like phenotypes in breast cancer. Cell Death Differ. 2015; 22(2):298-310

75. Schafer M, Werner S. Cancer as an overhealing wound: an old hypothesis revisited. Nat Rev Mol Cell Biol. 2008;9(8):628-38.

76. Bahnassy AA, Zekri AR, El-Bastawisy A, Fawzy A, Shetta M, Hussein N, Omran D, Ahmed AA, El-Labbody SS. Circulating tumor and cancer stem cells in hepatitis C virus-associated liver disease. World J Gastroenterol. 2014;20(48): 18240-8.

77. Donnelly JM, Engevik AC, Engevik M, Schumacher MA, Xiao C, Yang L, Worrell RT, Zavros Y. Gastritis promotes an activated bone marrow-derived mesenchymal stem cell with a phenotype reminiscent of a cancerpromoting cell. Dig Dis Sci. 2014;59(3):569-82.

78. Yong X, Tang B, Xiao YF, Xie R, Qin Y, Luo G, Hu CJ, Dong H, Yang SM. Helicobacter pylori upregulates Nanog and Oct4 via Wnt/beta-catenin signaling pathway to promote cancer stem cell-like properties in human gastric cancer. Cancer Lett. 2016;374(2):292-303.

79. Suzuki H, Iwasaki E, Hibi T. Helicobacter pylori and gastric cancer. Gastric Cancer. 2009;12(2):79-87.

80. Shigdar S, Li Y, Bhattacharya S, O'Connor M, Pu C, Lin J, Wang T, Xiang D, Kong $L$, Wei MQ, et al. Inflammation and cancer stem cells. Cancer Lett. 2014;345(2):271-8.

81. Lacina L, Plzak J, Kodet O, Szabo P, Chovanec M, Dvorankova B, Smetana K Jr. Cancer microenvironment: what can we learn from the stem cell niche. Int J Mol Sci. 2015;16(10):24094-110.

82. Bremnes RM, Donnem T, Al-Saad S, Al-Shibli K, Andersen S, Sirera R, Camps C, Marinez I, Busund LT. The role of tumor stroma in cancer progression and prognosis: emphasis on carcinoma-associated fibroblasts and non-small cell lung cancer. J Thorac Oncol. 2011;6(1):209-17.

83. O'Brien CA, Kreso A, Jamieson CH. Cancer stem cells and self-renewal. Clin Cancer Res. 2010;16(12):3113-20.

84. Blaylock RL. Cancer microenvironment, inflammation and cancer stem cells: a hypothesis for a paradigm change and new targets in cancer control. Surg Neurol Int. 2015;6:92.

85. Oshimori N, Oristian D, Fuchs E. TGF-beta promotes heterogeneity and drug resistance in squamous cell carcinoma. Cell. 2015;160(5):963-76.

86. Friedmann-Morvinski D, Verma IM. Dedifferentiation and reprogramming: origins of cancer stem cells. EMBO Rep. 2014;15(3):244-53.

87. Gupta PB, Chaffer CL, Weinberg RA. Cancer stem cells: mirage or reality? Nat Med. 2009;15(9):1010-2.

88. He G, Dhar D, Nakagawa H, Font-Burgada J, Ogata H, Jiang Y, Shalapour S, Seki E, Yost SE, Jepsen $\mathrm{K}$, et al. Identification of liver cancer progenitors whose malignant progression depends on autocrine IL-6 signaling. Cell. 2013;155(2):384-96.

89. Chaplin DD. Overview of the immune response. J Allergy Clin Immunol. 2010;125(2 Suppl 2):S3-23.

90. Chen L, Flies DB. Molecular mechanisms of T cell co-stimulation and coinhibition. Nat Rev Immunol. 2013;13(4):227-42.

91. Wada N, Gronthos S, Bartold PM. Immunomodulatory effects of stem cells. Periodontol. 2013;63(1):198-216.

92. Le Blanc K, Rasmusson I, Sundberg B, Gotherstrom C, Hassan M, Uzunel M, Ringden O. Treatment of severe acute graft-versus-host disease with third party haploidentical mesenchymal stem cells. Lancet. 2004; 363(9419):1439-41.

93. Rafei M, Campeau PM, Aguilar-Mahecha A, Buchanan M, Williams P, Birman E, Yuan S, Young YK, Boivin MN, Forner K, et al. Mesenchymal stromal cells ameliorate experimental autoimmune encephalomyelitis by inhibiting CD4 Th17 T cells in a CC chemokine ligand 2-dependent manner. J Immunol. 2009:182(10):5994-6002.

94. Cho KS, Park HK, Park HY, Jung JS, Jeon SG, Kim YK, Roh HJ. IFATS collection: immunomodulatory effects of adipose tissue-derived stem cells in an allergic rhinitis mouse model. Stem Cells. 2009;27(1):259-65.

95. Goodwin M, Sueblinvong V, Eisenhauer P, Ziats NP, LeClair L, Poynter ME, Steele C, Rincon M, Weiss DJ. Bone marrow-derived mesenchymal stromal cells inhibit Th2-mediated allergic airways inflammation in mice. Stem Cells. 2011;29(7):1137-48.
96. Haddad R, Saldanha-Araujo F. Mechanisms of T-cell immunosuppression by mesenchymal stromal cells: what do we know so far? Biomed Res Int. 2014; 2014:216806.

97. Zhao S, Wehner R, Bornhauser M, Wassmuth R, Bachmann M, Schmitz M. Immunomodulatory properties of mesenchymal stromal cells and their therapeutic consequences for immune-mediated disorders. Stem Cells Dev. 2010;19(5):607-14.

98. Zhao K, Lou R, Huang F, Peng Y, Jiang Z, Huang K, Wu X, Zhang Y, Fan Z, Zhou $\mathrm{H}$, et al. Immunomodulation effects of mesenchymal stromal cells on acute graft-versus-host disease after hematopoietic stem cell transplantation. Biol Blood Marrow Transplant. 2015;21(1):97-104.

99. Simonson OE, Mougiakakos D, Heldring N, Bassi G, Johansson HJ, Dalen M, Jitschin R, Rodin S, Corbascio M, El Andaloussi S, et al. In vivo effects of mesenchymal stromal cells in two patients with severe acute respiratory distress syndrome. Stem Cells Transl Med. 2015;4(10):1199-213.

100. Wilson JG, Liu KD, Zhuo H, Caballero L, McMillan M, Fang X, Cosgrove K, Vojnik R, Calfee CS, Lee JW, et al. Mesenchymal stem (stromal) cells for treatment of ARDS: a phase 1 clinical trial. Lancet Respir Med. 2015; 3(1):24-32.

101. Hirohashi Y, Torigoe T, Inoda S, Takahashi A, Morita R, Nishizawa S, Tamura $Y$, Suzuki $H$, Toyota M, Sato N. Immune response against tumor antigens expressed on human cancer stem-like cells/tumor-initiating cells. Immunotherapy. 2010;2(2):201-11.

102. Codony-Servat J, Rosell R. Cancer stem cells and immunoresistance: clinical implications and solutions. Transl Lung Cancer Res. 2015;4(6):689-703.

103. Chikamatsu K, Takahashi G, Sakakura K, Ferrone S, Masuyama K. Immunoregulatory properties of CD44+ cancer stem-like cells in squamous cell carcinoma of the head and neck. Head Neck. 2011;33(2):208-15.

104. Ye XZ, Xu SL, Xin YH, Yu SC, Ping YF, Chen L, Xiao HL, Wang B, Yi L, Wang $\mathrm{QL}$, et al. Tumor-associated microglia/macrophages enhance the invasion of glioma stem-like cells via TGF-beta1 signaling pathway. J Immunol. 2012; 189(1):444-53

105. Yang $L$, Zhang $Y$. Tumor-associated macrophages: from basic research to clinical application. J Hematol Oncol. 2017;10(1):58.

106. Malladi S, Macalinao DG, Jin X, He L, Basnet H, Zou Y, de Stanchina E, Massague J. Metastatic latency and immune evasion through autocrine inhibition of WNT. Cell. 2016;165(1):45-60.

107. Alhabbab RY. Targeting Cancer stem cells by genetically engineered chimeric antigen receptor T cells. Front Genet. 2020;11:312.

108. Yamashina T, Baghdadi M, Yoneda A, Kinoshita I, Suzu S, Dosaka-Akita H, Jinushi M. Cancer stem-like cells derived from chemoresistant tumors have a unique capacity to prime tumorigenic myeloid cells. Cancer Res. 2014; 74(10):2698-709.

109. Clayton SM, Archard JA, Wagner J, Farwell DG, Bewley AF, Beliveau A, Birkeland A, Rao S, Abouyared M, Belafsky PC, et al. Immunoregulatory potential of exosomes derived from cancer stem cells. Stem Cells Dev. 2020; 29(6):327-35.

110. Bi X, Hameed M, Mirani N, Pimenta EM, Anari J, Barnes BJ. Loss of interferon regulatory factor 5 (IRF5) expression in human ductal carcinoma correlates with disease stage and contributes to metastasis. Breast Cancer Res. 2011; 13(6):R111.

111. Martello G, Smith A. The nature of embryonic stem cells. Annu Rev Cell Dev Biol. 2014:30:647-75.

112. Efthymiou AG, Chen G, Rao M, Chen G, Boehm M. Self-renewal and cell lineage differentiation strategies in human embryonic stem cells and induced pluripotent stem cells. Expert Opin Biol Ther. 2014;14(9):1333-44.

113. Pearl O'Rourke P. Human pluripotent stem cells: NIH Guidelines. Mol Asp Med. 2001;22(3):165-70

114. Medema JP. Cancer stem cells: the challenges ahead. Nat Cell Biol. 2013; 15(4):338-44

115. Takebe N, Miele L, Harris PJ, Jeong W, Bando H, Kahn M, Yang SX, Ivy SP. Targeting Notch, Hedgehog, and Wnt pathways in cancer stem cells: clinical update. Nat Rev Clin Oncol. 2015;12(8):445-64.

116. Bhavanasi D, Klein PS. Wnt signaling in normal and malignant stem cells. Curr Stem Cell Rep. 2016;2(4):379-87.

117. Holland JD, Klaus A, Garratt AN, Birchmeier W. Wht signaling in stem and cancer stem cells. Curr Opin Cell Biol. 2013;25(2):254-64.

118. Komiya Y, Habas R. Wnt signal transduction pathways. Organogenesis. 2008; 4(2):68-75.

119. MacDonald BT, Tamai K, He X. Wnt/beta-catenin signaling: components, mechanisms, and diseases. Dev Cell. 2009;17(1):9-26. 
120. Baron R, Kneissel M. WNT signaling in bone homeostasis and disease: from human mutations to treatments. Nat Med. 2013;19(2):179-92.

121. Polakis P. Wnt signaling in cancer. Cold Spring Harb Perspect Biol. 2012;4(5): a008052.

122. Nusse R. Wnt signaling in disease and in development. Cell Res. 2005;15(1): 28-32.

123. Lin $\mathrm{CH}$, Ji T, Chen CF, Hoang BH. Wht signaling in osteosarcoma. Adv Exp Med Biol. 2014;804:33-45.

124. Ashihara E, Takada T, Maekawa T. Targeting the canonical Wnt/beta-catenin pathway in hematological malignancies. Cancer Sci. 2015;106(6):665-71.

125. Prosperi JR, Goss KH. A Wnt-ow of opportunity: targeting the Wnt/betacatenin pathway in breast cancer. Curr Drug Targets. 2010;11(9):1074-88.

126. Stewart DJ. Wnt signaling pathway in non-small cell lung cancer. J Natl Cancer Inst. 2014;106(1):djt356.

127. Malanchi I, Peinado H, Kassen D, Hussenet T, Metzger D, Chambon P, Huber M, Hohl D, Cano A, Birchmeier W, et al. Cutaneous cancer stem cell maintenance is dependent on beta-catenin signalling. Nature. 2008; 452(7187):650-3.

128. Majeti R, Becker MW, Tian Q, Lee TL, Yan X, Liu R, Chiang JH, Hood L, Clarke MF, Weissman IL. Dysregulated gene expression networks in human acute myelogenous leukemia stem cells. Proc Natl Acad Sci U S A. 2009;106(9): 3396-401.

129. Peifer M, Polakis P. Wnt signaling in oncogenesis and embryogenesis--a look outside the nucleus. Science. 2000;287(5458):1606-9.

130. Zhou Y, Kipps TJ, Zhang S. Wnt5a signaling in normal and cancer stem cells. Stem Cells Int. 2017;2017:5295286.

131. Leonard WJ, O'Shea JJ. Jaks and STATs: biological implications. Annu Rev Immunol. 1998;16:293-322.

132. Darnell JE Jr. STATs and gene regulation. Science. 1997;277(5332):1630-5.

133. Ivashkiv LB. Jak-STAT signaling pathways in cells of the immune system. Rev Immunogenet. 2000;2(2):220-30.

134. Yu $H$, Lee $H$, Herrmann A, Buettner $R$, Jove R. Revisiting STAT3 signalling in cancer: new and unexpected biological functions. Nat Rev Cancer. 2014; 14(11):736-46.

135. Schroeder A, Herrmann A, Cherryholmes G, Kowolik C, Buettner R, Pal S, Yu $\mathrm{H}$, Muller-Newen $\mathrm{G}$, Jove R. Loss of androgen receptor expression promotes a stem-like cell phenotype in prostate cancer through STAT3 signaling. Cancer Res. 2014:74(4):1227-37.

136. Groner B, von Manstein V. Jak Stat signaling and cancer: opportunities, benefits and side effects of targeted inhibition. Mol Cell Endocrinol. 2017; 451:1-14.

137. Herrmann A, Cherryholmes G, Schroeder A, Phallen J, Alizadeh D, Xin H, Wang T, Lee H, Lahtz C, Swiderski P, et al. TLR9 is critical for glioma stem cell maintenance and targeting. Cancer Res. 2014;74(18):5218-28.

138. Zhang $H$, Wang ZZ. Mechanisms that mediate stem cell self-renewal and differentiation. J Cell Biochem. 2008;103(3):709-18.

139. Schuringa JJ, Chung KY, Morrone G, Moore MA. Constitutive activation of STAT5A promotes human hematopoietic stem cell self-renewal and erythroid differentiation. J Exp Med. 2004;200(5):623-35.

140. Hernandez-Vargas H, Ouzounova M, Le Calvez-Kelm F, Lambert MP, McKayChopin S, Tavtigian SV, Puisieux A, Matar C, Herceg Z. Methylome analysis reveals Jak-STAT pathway deregulation in putative breast cancer stem cells. Epigenetics. 2011;6(4):428-39.

141. Sakaki-Yumoto M, Katsuno Y, Derynck R. TGF-beta family signaling in stem cells. Biochim Biophys Acta. 2013;1830(2):2280-96.

142. Heldin $\mathrm{CH}$, Miyazono $\mathrm{K}$, ten Dijke P. TGF-beta signalling from cell membrane to nucleus through SMAD proteins. Nature. 1997;390(6659):465-71.

143. Shi Y, Massague J. Mechanisms of TGF-beta signaling from cell membrane to the nucleus. Cell. 2003;113(6):685-700.

144. Miyazono K, ten Dijke P, Heldin CH. TGF-beta signaling by Smad proteins. Adv Immunol. 2000;75:115-57.

145. Jiang F, Mu J, Wang $X$, Ye $X$, Si L, Ning S, Li Z, Li Y. The repressive effect of miR-148a on TGF beta-SMADs signal pathway is involved in the glabridininduced inhibition of the cancer stem cells-like properties in hepatocellular carcinoma cells. PLoS One. 2014;9(5):e96698.

146. Reichrath J, Reichrath S. Notch signaling in embryology and cancer. New York: New York Springer-Verlag; 2012.

147. Borggrefe T, Oswald F. The notch signaling pathway: transcriptional regulation at notch target genes. Cell Mol Life Sci. 2009;66(10):1631-46.

148. Liu X, Fan D. The epithelial-mesenchymal transition and cancer stem cells: functional and mechanistic links. Curr Pharm Des. 2015;21(10):1279-91.
149. Choudhry Z, Rikani AA, Choudhry AM, Tariq S, Zakaria F, Asghar MW, Sarfraz MK, Haider K, Shafiq AA, Mobassarah NJ. Sonic hedgehog signalling pathway: a complex network. Ann Neurosci. 2014;21(1):28-31.

150. Roessler E, Belloni E, Gaudenz K, Jay P, Berta P, Scherer SW, Tsui LC, Muenke M. Mutations in the human sonic hedgehog gene cause holoprosencephaly. Nat Genet. 1996;14(3):357-60.

151. Campbell V, Copland M. Hedgehog signaling in cancer stem cells: a focus on hematological cancers. Stem Cells Cloning. 2015;8:27-38.

152. Katoh Y, Katoh M. Hedgehog signaling pathway and gastric cancer. Cancer Biol Ther. 2005:4(10):1050-4.

153. Taipale J, Beachy PA. The hedgehog and Wnt signalling pathways in cancer Nature. 2001;411(6835):349-54

154. Huang FT, Zhuan-Sun YX, Zhuang YY, Wei SL, Tang J, Chen WB, Zhang SN. Inhibition of hedgehog signaling depresses self-renewal of pancreatic cancer stem cells and reverses chemoresistance. Int J Oncol. 2012:41(5): 1707-14.

155. Kalluri R, Weinberg RA. The basics of epithelial-mesenchymal transition. J Clin Invest. 2009;119(6):1420-8.

156. Giepmans BN, van ljzendoorn SC. Epithelial cell-cell junctions and plasma membrane domains. Biochim Biophys Acta. 2009;1788(4):820-31.

157. Yang J, Weinberg RA. Epithelial-mesenchymal transition: at the crossroads of development and tumor metastasis. Dev Cell. 2008;14(6):818-29.

158. Thiery JP, Sleeman JP. Complex networks orchestrate epithelialmesenchymal transitions. Nat Rev Mol Cell Biol. 2006;7(2):131-42.

159. Stone RC, Pastar I, Ojeh N, Chen V, Liu S, Garzon Kl, Tomic-Canic M. Epithelial-mesenchymal transition in tissue repair and fibrosis. Cell Tissue Res. 2016;365(3):495-506.

160. De Craene B, Berx G. Regulatory networks defining EMT during cancer initiation and progression. Nat Rev Cancer. 2013;13(2):97-110.

161. Tsai JH, Yang J. Epithelial-mesenchymal plasticity in carcinoma metastasis. Genes Dev. 2013;27(20):2192-206

162. Yamamoto M, Sakane K, Tominaga K, Gotoh N, Niwa T, Kikuchi Y, Tada K, Goshima N, Semba K, Inoue Jl. Intratumoral bidirectional transitions between epithelial and mesenchymal cells in triple-negative breast cancer. Cancer Sci. 2017;108(6):1210-22.

163. Hao J, Zhang Y, Deng M, Ye R, Zhao S, Wang Y, Li J, Zhao Z. MicroRNA control of epithelial-mesenchymal transition in cancer stem cells. Int J Cancer. 2014;135(5):1019-27.

164. Scheel C, Weinberg RA. Phenotypic plasticity and epithelial-mesenchymal transitions in cancer and normal stem cells? Int J Cancer. 2011;129(10):2310-4.

165. Micalizzi DS, Farabaugh SM, Ford HL. Epithelial-mesenchymal transition in cancer: parallels between normal development and tumor progression. J Mammary Gland Biol Neoplasia. 2010;15(2):117-34.

166. Strizzi L, Bianco C, Normanno N, Salomon D. Cripto-1: a multifunctional modulator during embryogenesis and oncogenesis. Oncogene. 2005;24(37): 5731-41.

167. Wu Y, Zhou BP. Snail: more than EMT. Cell Adhes Migr. 2010;4(2):199-203.

168. Krebs AM, Mitschke J, Lasierra Losada M, Schmalhofer O, Boerries M, Busch $\mathrm{H}$, Boettcher M, Mougiakakos D, Reichardt W, Bronsert P, et al. The EMTactivator Zeb1 is a key factor for cell plasticity and promotes metastasis in pancreatic cancer. Nat Cell Biol. 2017;19(5):518-29.

169. Zhou W, Lv R, Qi W, Wu D, Xu Y, Liu W, Mou Y, Wang L. Snail contributes to the maintenance of stem cell-like phenotype cells in human pancreatic cancer. PLoS One. 2014;9(1):e87409.

170. Ota I, Masui T, Kurihara M, Yook Jl, Mikami S, Kimura T, Shimada K, Konishi N, Yane K, Yamanaka T, et al. Snail-induced EMT promotes cancer stem celllike properties in head and neck cancer cells. Oncol Rep. 2016;35(1):261-6.

171. Jung HY, Yang J. Unraveling the TWIST between EMT and cancer stemness. Cell Stem Cell. 2015;16(1):1-2.

172. Wang Z, Li Y, Kong D, Sarkar FH. The role of notch signaling pathway in epithelial-mesenchymal transition (EMT) during development and tumor aggressiveness. Curr Drug Targets. 2010;11(6):745-51.

173. Timmerman LA, Grego-Bessa J, Raya A, Bertran E, Perez-Pomares JM, Diez J, Aranda S, Palomo S, McCormick F, Izpisua-Belmonte JC, et al. Notch promotes epithelial-mesenchymal transition during cardiac development and oncogenic transformation. Genes Dev. 2004;18(1):99-115.

174. Espinoza I, Pochampally R, Xing F, Watabe K, Miele L. Notch signaling: targeting cancer stem cells and epithelial-to-mesenchymal transition. Onco Targets Ther. 2013;6:1249-59.

175. Nicolas FE, Lopez-Martinez AF. MicroRNAs in human diseases. Recent Pat DNA Gene Seq. 2010;4(3):142-54 
176. Felekkis K, Touvana E, Stefanou C. Deltas C: microRNAs: a newly described class of encoded molecules that play a role in health and disease. Hippokratia. 2010;14(4):236-40.

177. Moss EG, Poethig RS. MicroRNAs: something new under the sun. Curr Biol. 2002;12(20):R688-90.

178. Zhang J, Ma L. MicroRNA control of epithelial-mesenchymal transition and metastasis. Cancer Metastasis Rev. 2012;31(3-4):653-62.

179. Chakraborty C, Shah KD, Cao WG, Hsu CH, Wen ZH, Lin CS. Potentialities of induced pluripotent stem (iPS) cells for treatment of diseases. Curr Mol Med. 2010;10(8):756-62.

180. Chakraborty C, S SR, M JH, Agoramoorthy G. Network analysis of transcription factors for nuclear reprogramming into induced pluripotent stem cell using bioinformatics. Cell J. 2014;15(4):332-9.

181. Tay Y, Zhang J, Thomson AM, Lim B, Rigoutsos I. MicroRNAs to Nanog, Oct4 and Sox2 coding regions modulate embryonic stem cell differentiation. Nature. 2008;455(7216):1124-8.

182. Kedmi M, Sas-Chen A, Yarden Y. MicroRNAs and growth factors: an alliance propelling tumor progression. J Clin Med. 2015;4(8):1578-99.

183. Di Leva G, Garofalo M, Croce CM. MicroRNAs in cancer. Annu Rev Pathol. 2014;9:287-314.

184. Bachour T, Bennett K. The role of microRNAs in breast cancer. J Assoc Genet Technol. 2011;37(1):21-8.

185. Song J, Bai Z, Zhang Z. MicroRNAs are implicated in the initiation and progression of gastric cancer. Chin Med J. 2014;127(3):554-9.

186. Xia L, Ren Y, Fang X, Yin Z, Li X, Wu W, Guan P, Zhou B. Prognostic role of common microRNA polymorphisms in cancers: evidence from a metaanalysis. PLoS One. 2014;9(10):e106799.

187. Park SM, Gaur AB, Lengyel E, Peter ME. The miR-200 family determines the epithelial phenotype of cancer cells by targeting the E-cadherin repressors ZEB1 and ZEB2. Genes Dev. 2008;22(7):894-907.

188. Korpal M, Kang Y. The emerging role of miR-200 family of microRNAs in epithelial-mesenchymal transition and cancer metastasis. RNA Biol. 2008, 5(3):115-9.

189. Taube JH, Malouf GG, Lu E, Sphyris N, Vijay V, Ramachandran PP, Ueno KR, Gaur S, Nicoloso MS, Rossi S, et al. Epigenetic silencing of microRNA-203 is required for EMT and cancer stem cell properties. Sci Rep. 2013;3:2687.

190. Croker AK, Goodale D, Chu J, Postenka C, Hedley BD, Hess DA, Allan AL. High aldehyde dehydrogenase and expression of cancer stem cell markers selects for breast cancer cells with enhanced malignant and metastatic ability. J Cell Mol Med. 2009;13(8B):2236-52.

191. Dragu DL, Necula LG, Bleotu C, Diaconu CC, Chivu-Economescu M. Therapies targeting cancer stem cells: current trends and future challenges. World J Stem Cells. 2015;7(9):1185-201.

192. Yan Y, Zuo X, Wei D. Concise review: emerging role of CD44 in cancer stem cells: a promising biomarker and therapeutic target. Stem Cells Transl Med. 2015;4(9):1033-43.

193. Jin L, Hope KJ, Zhai Q, Smadja-Joffe F, Dick JE. Targeting of CD44 eradicates human acute myeloid leukemic stem cells. Nat Med. 2006;12(10):1167-74.

194. Pan Q, Li Q, Liu S, Ning N, Zhang X, Xu Y, Chang AE, Wicha MS. Concise review: targeting cancer stem cells using immunologic approaches. Stem Cells. 2015;33(7):2085-92

195. Deleo AB. Targeting cancer stem cells with ALDH1A1-based immunotherapy. Oncoimmunology. 2012;1(3):385-7.

196. Krause DS, Fackler MJ, Civin Cl, May WS. CD34: structure, biology, and clinical utility. Blood. 1996:87(1):1-13.

197. Zhang S, Balch C, Chan MW, Lai HC, Matei D, Schilder JM, Yan PS, Huang TH, Nephew KP. Identification and characterization of ovarian cancer-initiating cells from primary human tumors. Cancer Res. 2008;68(11):4311-20.

198. Chen K, Huang YH, Chen JL. Understanding and targeting cancer stem cells: therapeutic implications and challenges. Acta Pharmacol Sin. 2013;34(6):732-40.

199. Liu G, Yuan X, Zeng Z, Tunici P, Ng H, Abdulkadir IR, Lu L, Irvin D, Black KL, Yu JS. Analysis of gene expression and chemoresistance of CD133+ cancer stem cells in glioblastoma. Mol Cancer. 2006:5:67.

200. Tardio JC. CD34-reactive tumors of the skin. An updated review of an evergrowing list of lesions. J Cutan Pathol. 2009;36(1):89-102.

201. Pontier SM, Muller WJ. Integrins in mammary-stem-cell biology and breastcancer progression--a role in cancer stem cells? J Cell Sci. 2009;122(Pt 2): 207-14

202. Liu S, Dontu G, Mantle ID, Patel S, Ahn NS, Jackson KW, Suri P, Wicha MS. Hedgehog signaling and Bmi-1 regulate self-renewal of normal and malignant human mammary stem cells. Cancer Res. 2006;66(12):6063-71.
203. Salcido CD, Larochelle A, Taylor BJ, Dunbar CE, Varticovski L. Molecular characterisation of side population cells with cancer stem cell-like characteristics in small-cell lung cancer. Br J Cancer. 2010;102(11):1636-44.

204. Brungs D, Aghmesheh M, Vine KL, Becker TM, Carolan MG, Ranson M. Gastric cancer stem cells: evidence, potential markers, and clinical implications. J Gastroenterol. 2016;51(4):313-26.

205. Horst D, Kriegl L, Engel J, Kirchner T, Jung A. CD133 expression is an independent prognostic marker for low survival in colorectal cancer. $\mathrm{Br}$ J Cancer. 2008;99(8):1285-9.

206. Lukacs RU, Memarzadeh S, Wu H, Witte ON. Bmi-1 is a crucial regulator of prostate stem cell self-renewal and malignant transformation. Cell Stem Cell. 2010;7(6):682-93.

207. Zoller M. CD44: can a cancer-initiating cell profit from an abundantly expressed molecule? Nat Rev Cancer. 2011;11(4):254-67.

208. Ponnusamy MP, Batra SK. Ovarian cancer: emerging concept on cancer stem cells. J Ovarian Res. 2008;1(1):4.

209. Kwiatkowska-Borowczyk EP, Gabka-Buszek A, Jankowski J, Mackiewicz A Immunotargeting of cancer stem cells. Contemp Oncol (Pozn). 2015;19(1A): A52-9.

210. Deluiz D, Delcroix GJ, D'Ippolito G, Grau-Monge C, Bonnin-Marquez A Reiner T, Tinoco EMB, Amadeu T, Pires FR, Schiller PC. Human bone marrow-derived mesenchymal stromal cell-seeded bone biomaterial directs fast and superior mandibular bone augmentation in rats. Sci Rep. 2019;9(1): 11806.

211. Beziat G, Ysebaert L. Tagraxofusp for the treatment of blastic plasmacytoid dendritic cell neoplasm (BPDCN): a brief report on emerging data. Onco Targets Ther. 2020;13:5199-205.

212. Gilligan KE, Dwyer RM. Engineering exosomes for cancer therapy. Int J Mol Sci. 2017;18(6):1122.

213. Colombo M, Raposo G, Thery C. Biogenesis, secretion, and intercellular interactions of exosomes and other extracellular vesicles. Annu Rev Cell Dev Biol. 2014;30:255-89

214. Wang J, Zheng Y, Zhao M. Exosome-based cancer therapy: implication for targeting cancer stem cells. Front Pharmacol. 2016;7:533.

215. Wolska-Washer A, Robak T. Glasdegib in the treatment of acute myeloid leukemia. Future Oncol. 2019;15(28):3219-32.

216. Tu LC, Foltz G, Lin E, Hood L, Tian Q. Targeting stem cells-clinical implications for cancer therapy. Curr Stem Cell Res Ther. 2009;4(2):147-53.

217. Formenti SC, Lee P, Adams S, Goldberg JD, Li X, Xie MW, Ratikan JA, Felix C, Hwang L, Faull KF, et al. Focal irradiation and systemic TGFbeta blockade in metastatic breast cancer. Clin Cancer Res. 2018;24(11):2493-504.

218. Zhou S, Abdouh M, Arena V, Arena M, Arena GO. Reprogramming malignant cancer cells toward a benign phenotype following exposure to human embryonic stem cell microenvironment. PLoS One. 2017;12(1): e0169899.

219. Garg M. MicroRNAs, stem cells and cancer stem cells. World J Stem Cells. 2012;4(7):62-70

220. Han M, Liu M, Wang Y, Chen X, Xu J, Sun Y, Zhao L, Qu H, Fan Y, Wu C. Antagonism of miR-21 reverses epithelial-mesenchymal transition and cancer stem cell phenotype through AKT/ERK1/2 inactivation by targeting PTEN. PLoS One. 2012;7(6):e39520.

221. Asadzadeh Z, Mansoori B, Mohammadi A, Aghajani M, Haji-Asgarzadeh K, Safarzadeh E, Mokhtarzadeh A, Duijf PHG, Baradaran B. microRNAs in cancer stem cells: biology, pathways, and therapeutic opportunities. J Cell Physiol. 2019:234(7):10002-17.

\section{Publisher's Note}

Springer Nature remains neutral with regard to jurisdictional claims in published maps and institutional affiliations. 